\title{
Preparation of polymer incarcerated gold nanocluster catalysts (PI-Au) and their application to aerobic oxidation reactions of boronic acids, alcohols, and silyl enol ethers
}

\author{
Hiroyuki Miyamura, Tomohiro Yasukawa, Shū Kobayashi* \\ ${ }^{a}$ Department of Chemistry, School of Science, The University of Tokyo, Hongo, Bunkyo-ku, Tokyo 113-0033 (Japan)
}

\section{ARTICLE INFO}

Article history:

Received

Received in revised form

Accepted

Available online

Keywords:

gold nanocluster

polystyrene

heterogeneous catalyst

aerobic oxidation

silyl enol ether

\section{ABSTRACT}

Heterogeneous gold nanocluster catalysts immobilized by the method known as polymer incarceration were prepared. Polystyrene-derived polymers with epoxide and alcohol moieties, which could be cross-linked under heating conditions, were employed as supports for their preparation. Cationic gold salts were reduced in a solution of $\mathrm{NaBH}_{4}$ and the polymers. Poor solvents for the polymers were added, and the polymers were precipitated and encapsulated gold nanoclusters with weak but multiple interactions between a gold nanocluster surface and the $\pi$ electrons of benzene rings. The polymer capsules were heated under neat conditions to afford heterogeneous gold nanocluster catalysts; namely, polymer-incarcerated gold nanoclusters. The catalysts thus prepared could be applied to the aerobic oxidation of phenyl boronic acids, alcohols, and silyl enol ethers. We found that the choice of polymers, good and poor solvents for the polymers, metal loadings, heating conditions for cross-linking, and final activation were all crucial for obtaining high-activity catalysts.

2009 Elsevier Ltd. All rights reserved.

\section{Introduction}

Since Haruta's discovery of gold nanocluster catalyzed aerobic oxidation of carbon monoxide at low temperature, ${ }^{1,2}$ various research groups, including us, have developed various aerobic oxidation reactions. ${ }^{3-10}$ In particular, the oxidation of alcohols to carbonyl compounds, ${ }^{3-5}$ oxidation of amines to imines, ${ }^{11-14}$ and oxidative coupling reactions of aryl boronic acids $^{15-19}$ have received much attention recently.

Scheme 1. Microencapsulation and Polymer Incarceration
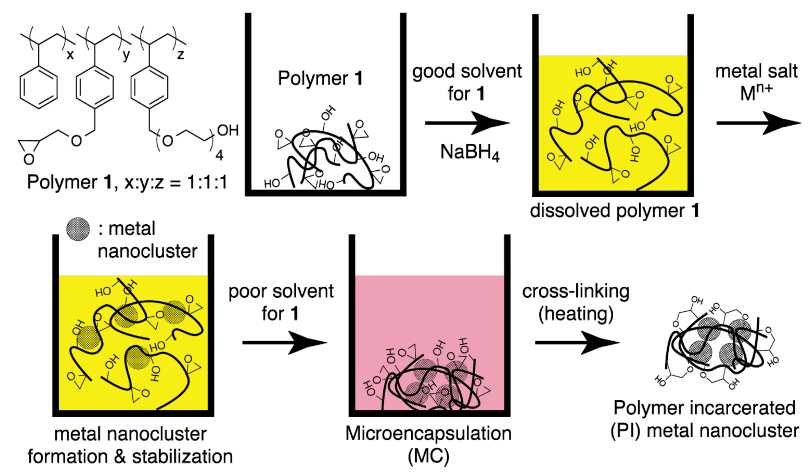

We are currently engaged in the extensive development of heterogeneous metal nanoparticle catalysts for various reactions; namely, microencapsulation and polymer incarceration, ${ }^{20-24}$ such as aerobic oxidations, ${ }^{25-30}$ hydrogenations ${ }^{24,31}$ and C-C-bondforming reactions. ${ }^{32-34}$ These developments are based on our original techniques. Among these catalysts, gold ${ }^{35-47}$ and its bimetallic nanocluster incarcerated catalysts, ${ }^{48-53}$ prepared using polystyrene-based polymers with cross-linking moieties, show particularly high reactivity for multimodal aerobic oxidative transformations under mild conditions, including tandem oxidative processes. ${ }^{42-45,47,49,51-54}$ Furthermore, multifunctional catalysts in which metal nanoclusters and metal complexes or organocatalysts are combined can be fabricated to achieve reaction integration of, for example, aerobic oxidation and $\mathrm{C}-\mathrm{C}-$ bond-forming reactions. ${ }^{52,53}$ Metal nanoclusters can be 'locked up' within polymer matrixes by the interaction between the nanocluster surface and the $\pi$ electrons of benzene rings ${ }^{55-58}$ in polymer structures and by the physical envelopment using crosslinkages.

First, a polystyrene derivative with cross-linking moieties and a reductant are dissolved in a good solvent for the polymer (Scheme 1). A metal salt solution is added dropwise. Reduction occurs immediately, and nanoclusters are formed. In situ prepared nanoclusters are stabilized by the dissolved polymer to avoid aggregation. A poor solvent for the polymer is added, and polymer precipitation occurs. At this stage, metal nanoclusters can co-precipitate with the polymer because of weak but multiple interactions between polymer side chains and the nanocluster surface. The solvent is removed by decantation, and the remaining solid is heated under neat conditions to create cross- 
links. The catalyst thus prepared is insoluble in almost all solvents. On the other hand, the catalyst swells well in various organic solvents; thus, it can function as a 'semihomogeneous' catalyst and show activity equivalent to or higher than the original homogeneous catalyst for various organic transformations. Furthermore, the catalyst can be easily separated from reaction mixtures by simple operations and then reused several times without loss of activity or leaching of metals. Moreover, it can be successfully applied to flow systems, which can be extended to scaled-up under industrial scale and reaction integrations. ${ }^{46,48,59,60}$

In 2007, we reported the first preparation of polymerincarcerated gold nanocluster catalysts (PI-Au) and their application to the aerobic oxidation of alcohols under mild conditions. ${ }^{39}$ After this seminal development, our PI-Au were expanded to a number of aerobic oxidation reactions, such as the oxidation of hydroquinones, ${ }^{41}$ aldehydes,${ }^{36}$ amines, ${ }^{40}$ and 1,3dicarbonyl compounds, ${ }^{38}$ direct oxidative esterification, ${ }^{42,47}$ oxidative amidation and oxidative imine formation from alcohols and amines. ${ }^{43-45,51}$ During these investigations, we acknowledged several important factors in the preparation of PI-Au. The following are all crucial for the activity of these catalysts: the metal loading, the choice of combination of a poor solvent and a good solvent, and the heating conditions during cross-linking.

Herein, we report more detailed investigations into the preparation of $\mathrm{PI}-\mathrm{Au}$ and further extensions of our work on aerobic oxidation reactions using $\mathrm{PI}-\mathrm{Au}$, such as the oxidative homo-coupling of aryl boronic acids and the oxidation of silyl enol ethers, as well as alcohol oxidation reactions.

\section{Results and discussion}

Organic-polymer-immobilized heterogeneous $\mathrm{Au}$ nanocluster catalysts were initially limited compared with inorganic-supportimmobilized ones, although Tsukuda, Sakurai and co-workers reported Au:PVP as a quasi-homogeneous catalyst that can be used in water. ${ }^{61}$ We hypothesized that Au nanoclusters prepared in organic solvents and immobilized directly on organic supports could be efficient catalysts for various organic syntheses. Besides this, it is known that aromatic molecules such as benzene and toluene can interact weakly with a gold surface or $\mathrm{Au}$ nanoclusters via their $\pi$ electrons. Therefore, we hypothesized that if $\mathrm{Au}$ nanoclusters could be stabilized by weak but multiple interactions with aromatic parts of polymers, these $\mathrm{Au}$ nanoclusters would become very effective and versatile catalysts for organic syntheses.

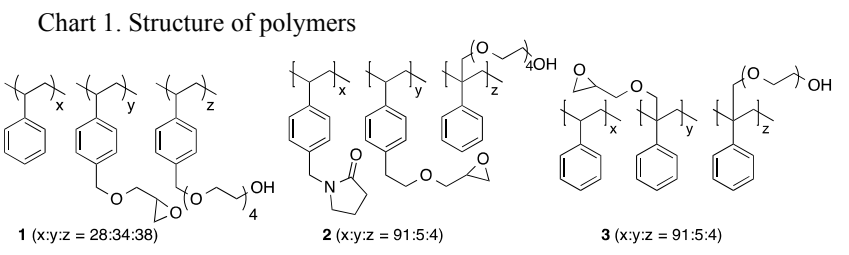

Table 1

Preparation of PI-Au

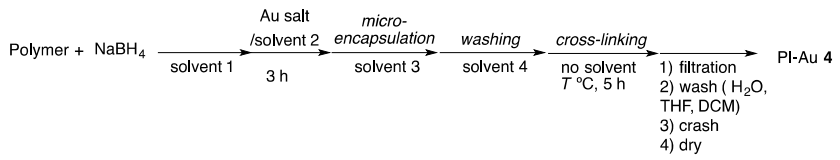

\begin{tabular}{|c|c|c|c|c|c|c|c|c|}
\hline \multirow[b]{2}{*}{ entry } & \multirow{2}{*}{\begin{tabular}{|c|} 
pol \\
yme \\
r \\
\end{tabular}} & \multirow{2}{*}{$\mathrm{Au}$ salt } & \multicolumn{4}{|l|}{ Solvent } & \multirow{2}{*}{$\begin{array}{l}{[\mathrm{T}]} \\
\left({ }^{\circ} \mathrm{C}\right)\end{array}$} & \multirow{2}{*}{$\begin{array}{c}\text { PI-Au } \\
\text { [loading } \\
(\mathrm{mmol} / \mathrm{g})]\end{array}$} \\
\hline & & & 1 & 2 & 3 & 4 & & \\
\hline 1 & 3 & $\mathrm{HAuCl}_{4}$ & THF & THF & hexane & hexane & 120 & 4a [0.061] \\
\hline 2 & 2 & $\mathrm{HAuCl}_{4}$ & THF & THF & hexane & hexane & 120 & 4b [0.217] \\
\hline
\end{tabular}

\begin{tabular}{|c|c|c|c|c|c|c|c|c|}
\hline 3 & 1 & $\mathrm{HAuCl}_{4}$ & THF & THF & hexane & hexane & $\mathrm{-a}^{\mathrm{a}}$ & - \\
\hline 4 & 1 & $\mathrm{AuClPPh}_{3}$ & THF & THF & hexane & hexane & 150 & 4c $[0.318]$ \\
\hline 5 & 1 & $\mathrm{AuClPPh}_{3}$ & THF & THF & hexane & hexane & 150 & 4d [0.163] \\
\hline 6 & 1 & $\mathrm{AuClPPh}_{3}$ & THF & THF & hexane & hexane & 150 & $\mathbf{4 e}[0.103]$ \\
\hline 7 & 1 & $\mathrm{AuClPPh}_{3}$ & THF & THF & hexane & hexane & 150 & 4f $[0.079]$ \\
\hline 8 & 1 & $\mathrm{AuClPPh}_{3}$ & diglyme & diglyme & hexane & hexane & 150 & $4 \mathbf{g}[0.080]$ \\
\hline 9 & 1 & $\mathrm{AuClPPh}_{3}$ & diglyme & THF & hexane & $\mathrm{Et}_{2} \mathrm{O}$ & 150 & 4h [0.062] \\
\hline 10 & 1 & $\mathrm{AuClPPh}_{3}$ & diglyme & THF & $\mathrm{Et}_{2} \mathrm{O}$ & $\mathrm{Et}_{2} \mathrm{O}$ & 150 & $4 \mathrm{i}[0.073]$ \\
\hline 11 & 1 & $\mathrm{AuClPPh}_{3}$ & diglyme & THF & $\mathrm{Et}_{2} \mathrm{O}$ & $\begin{array}{l}\mathrm{Et}_{2} \mathrm{O} \\
/ \mathrm{H}_{2} \mathrm{O} \\
\end{array}$ & 150 & $4 \mathbf{j}[0.071]$ \\
\hline
\end{tabular}

${ }^{a}$ Metallic gold was precipitated before microencapsulation.

We commenced our investigation to confirm whether $\mathrm{Au}$ nanoclusters could be stabilized by benzene rings in polystyrene derivatives (Chart 1). We chose $\mathrm{HAuCl}_{4}$ as a gold source and $\mathrm{NaBH}_{4}$ as a reductant, which have been widely used for the preparation of $\mathrm{Au}$ nanoclusters in aqueous media (Table 1). Polystyrene-based polymer 3 with cross-linking moieties, which was used for polymer-micelle incarcerated metal catalysts, was dissolved in THF, and $\mathrm{NaBH}_{4}$ was suspended therein. $\mathrm{HAuCl}_{4}$ in THF was slowly added, and the solution immediately turned red/purple, which indicated the formation of $\mathrm{Au}$ nanoclusters. Microencapsulation was conducted by the addition of hexane as a poor solvent. The resulting solid was separated by decantation and then heated at $120^{\circ} \mathrm{C}$ to form a heterogeneous catalyst, PI$\mathrm{Au} \mathbf{4 a}$, by the cross-linking of side chains (Table 1, entry 1). PI$\mathrm{Au} \mathbf{4 b}$ was also prepared with polystyrene-based polymers with more polar units (polymer 2) (Chart 1; Table 1, entry 2). Catalytic activities of the catalysts thus prepared were tested for the oxidative homo-coupling of phenyl boronic acid in basic water solution; however, no reaction proceeded (Table 2, entries 1 and 2). To increase the hydrophilicity of the catalyst, polymer 1, which contained more tetraethylene glycol units, was employed for the preparation of PI-Au; however, bulk gold precipitation occurred before microencapsulation (Table 1, entry 3). The gold source was then changed to $\mathrm{AuClPPh}_{3}$ from $\mathrm{HAuCl}_{4}$. No precipitation occurred, even with polymer $\mathbf{1}$ as the support. After microencapsulation, upon the addition of hexane, the precipitate was heated under neat conditions, and PI-Au 4c was prepared as a red/purple solid with $0.318 \mathrm{mmol} / \mathrm{g}$ Au loading (Table 1, entry 4; Figure 1). PI-Au 4c gave the desired homocoupling product in low yield in a basic water solution (Table 2, entry 3). Biphasic solvent systems were investigated. Use of a water-dichloromethane (water-DCM) mixed solvent system gave improved yields (Table 2, entries 4-6). TEM analysis revealed that the cluster size became smaller as the loading of PI$\mathrm{Au}$ decreased (Table 1, entries 4-7; Figures 1-4). When Au loadings were higher than $0.1 \mathrm{mmol} / \mathrm{g}$, larger nanoparticles or aggregation of small to medium size nanoparticles were observed (Figures 1-3). On the other hand, PI-Au 4f with a lower Au loading of $0.079 \mathrm{mmol} / \mathrm{g}$ contained small nanoclusters $(2-3 \mathrm{~nm})$ mainly with less aggregation of them (Figure 4), and the homocoupling reaction was conducted (Table 1 , entry 7 ). The desired homo-coupling product was obtained in $82 \%$ yield. This catalyst could be recovered by simple filtration and reused at least three times (Table 2, entries 7-9). The nanocluster size of PI-Au after these uses did not change from the original size of PI-Au before use (Figure 5).

PI-Au 4f was also applied to the aerobic oxidation of secphenethyl alcohol and showed high activity in a water-DCM mixed solvent system in the presence of $\mathrm{K}_{2} \mathrm{CO}_{3}$ (Table 3, entries 1 and 2). PI-Au $\mathbf{4 f}$ could be reused (Table 3, entries 2-4) for this reaction, and $\alpha, \alpha, \alpha$-trifluorotoluene (BTF) could be employed as a greener solvent instead of DCM (Table 3, entry 6). PI-Au (4e and 4d) with higher Au loading showed lower reactivity than PI$\mathrm{Au}$ 4f (Table 3, entries 6-8). PI-Au 4c, 4g and 4h contained 
larger Au nanoclusters than PI-Au 4f. This might be the reason for the difference in reactivities.
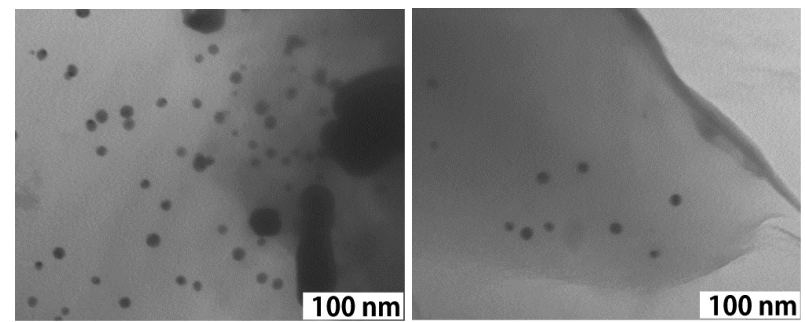

Fig. 1. Typical TEM images of PI-Au 4c.

Although PI-Au 4f contained smaller Au nanoclusters, larger clusters $(>5 \mathrm{~nm})$ were also present. To improve the homogeneity of the $\mathrm{Au}$ nanoclusters, we reexamined the catalyst preparation method. When we used THF during the reduction of Au salts with $\mathrm{NaBH}_{4}$, the $\mathrm{NaBH}_{4}$ was suspended in the solution because of its low solubility. We then employed diethylene glycol dimethyl ether (diglyme) because it dissolves $\mathrm{NaBH}_{4}$ well. A completely homogeneous solution was now obtained before the addition of a poor solvent for microencapsulation. When hexane was used as a poor solvent and a washing solvent after microencapsulation, a sticky precipitate containing diglyme was obtained, and PI-Au $\mathbf{4 g}$ was prepared (Table 1, entry 8). PI-Au $\mathbf{4 g}$ showed rather low activity for alcohol oxidation (Table 3, entry 9). Diglyme was absorbed in the polymer precipitate before cross-linking, which might cause insufficient crosslinking. We therefore changed the washing solvent after microencapsulation from hexane to diethyl ether. However, the catalyst thus prepared, PI-Au $\mathbf{4 h}$, still showed low reactivity (Table 1, entry 9; Table 3, entry 10). To remove all the diglyme from the polymer precipitate after microencapsulation, we chose to use diethyl ether as the poor solvent for microencapsulation and then for washing because diethyl ether and diglyme mix well. The catalyst thus prepared, PI-Au 4i, became a fine powder after cross-linking and showed excellent activity for alcohol oxidation (Table 1, entry 10; Table 3 , entry 11; Figure 6). We also aimed to remove the excess reductant, $\mathrm{NaBH}_{4}$, before crosslinking, by washing with an aqueous solution. PI-Au $4 \mathbf{j}$ prepared according to this procedure was, however, not a fine powder; it was a sticky solid and showed almost no activity (Table 1, entry 11; Table 3, entry 12). We postulated that a remaining tetravalent or trivalent borate complex, made from $\mathrm{NaBH}_{4}$, and alcohol moieties in the polymer side chains played important roles during the cross-linking step, as a borate complex could be immobilized in the same polymer and enter into cross-linked polymer capsules containing Au-Pd bimetallic nanoclusters during preparation of $\mathrm{Au} / \mathrm{Pd} / \mathrm{B}$ multi-metallic catalyst for tandem oxidation-Michael addition reaction. ${ }^{51}$
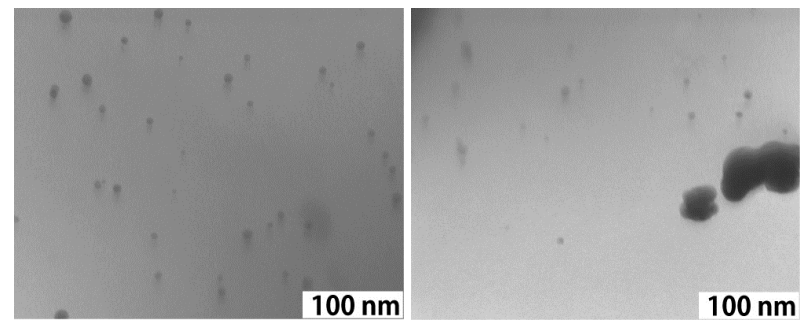

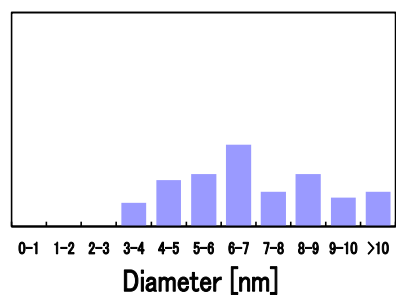

Fig. 2. Typical TEM images and size distributions of PI-Au 4d. Average size of clusters: $7.0 \pm 2.3 \mathrm{~nm}$

Next we evaluated the catalytic activities of the PI-Au more strictly by reducing the reaction time of the aerobic oxidation of the alcohol. The reaction times used were $3 \mathrm{~h}$ and $5 \mathrm{~h}$ (Table 4). PI-Au 4i, which was the best catalyst thus far, afforded the desired ketone in $74 \%$ yield after $3 \mathrm{~h}$ (entry 1 ). We then included a second heating step in the preparation method and changed the reaction temperature and time for both the first and the second heating steps (Scheme 2). PI-Au 4k-4p prepared by the method that includes the two heating steps $\left(\mathrm{T}_{1}\right.$ and $\left.\mathrm{T}_{2}\right)$ afforded the desired ketone in excellent yield for the reaction time of $5 \mathrm{~h}$ (entries 2-7). In particular, the catalysts $4 \mathbf{l}-\mathbf{4 n}$, whose heating temperature was $150{ }^{\circ} \mathrm{C}$, showed excellent yields, even for the reaction time of $3 \mathrm{~h}$ (entries 3-5). It was also found that if the catalysts were heated twice, the heating time could be varied (1$5 \mathrm{~h})$.

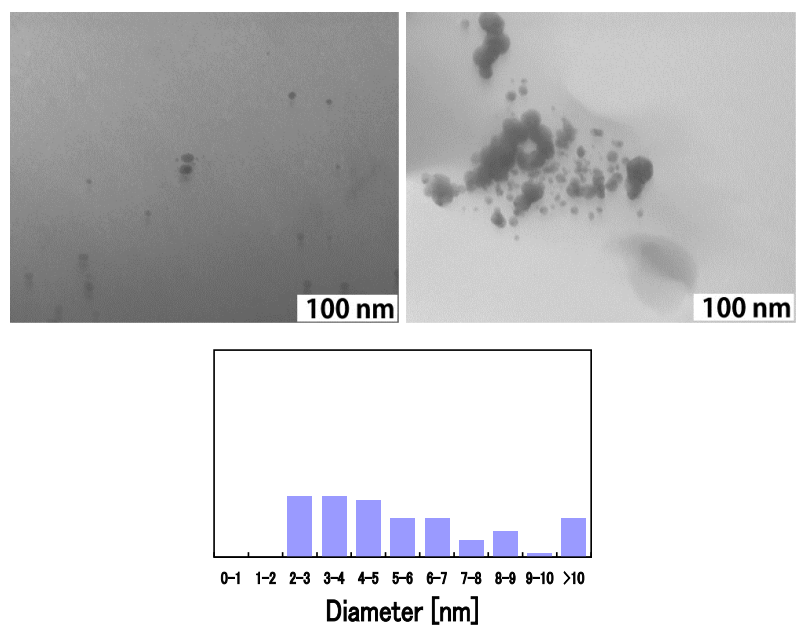

Fig. 3. Typical TEM images and size distribution of PI-Au 4e. Average size of clusters: $5.6 \pm 3.5 \mathrm{~nm}$

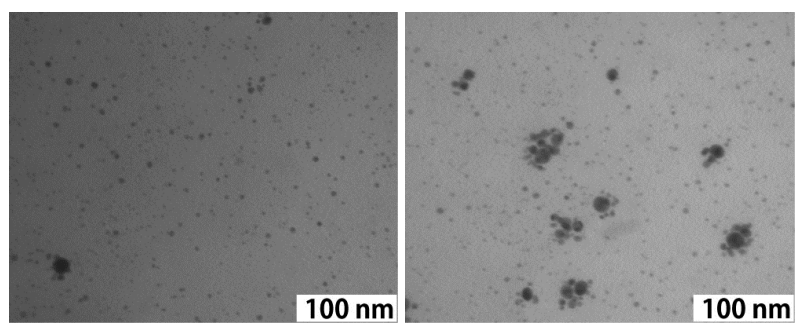




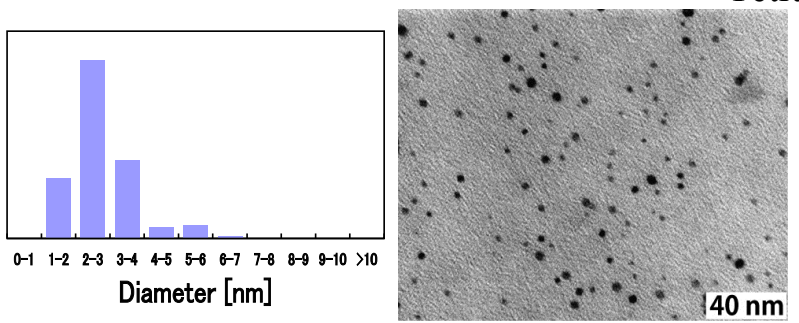

Fig. 4. Typical TEM images and size distribution of PI-Au 4f. Average size of clusters: $2.8 \pm 0.9 \mathrm{~nm}$

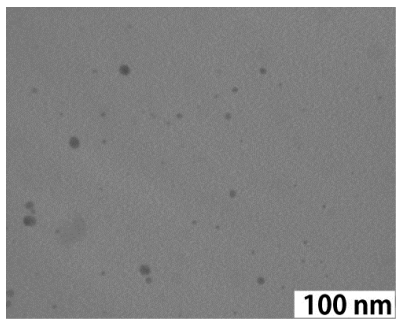

Fig. 5. Typical TEM image of PI-Au $\mathbf{4 f}$ after use for homo-coupling of phenyl boronic acid.

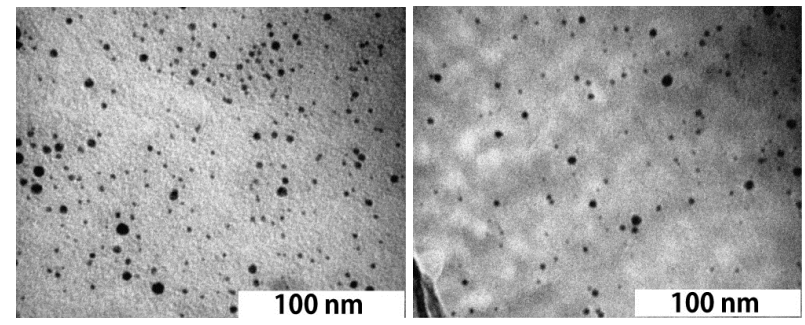

Fig. 6. Typical TEM images of PI-Au 4i.

Table 2

Oxidative homo-coupling of phenyl boronic acid

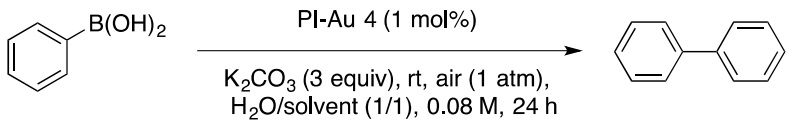

\begin{tabular}{|c|c|c|c|}
\hline Entry & PI-Au & Solvent & Yield (\%) $^{\mathrm{a}}$ \\
\hline 1 & 4a & none & 0 \\
\hline 2 & 4b & none & 0 \\
\hline 3 & 4c & none & 2 \\
\hline 4 & 4c & hexane & 3 \\
\hline 5 & 4c & EtOAc & 17 \\
\hline 6 & 4c & DCM & 25 \\
\hline 7 & 4f & DCM & 82 \\
\hline 8 & reuse of entry 7 & DCM & 82 \\
\hline 9 & reuse of entry 7 & DCM & 80 \\
\hline
\end{tabular}

${ }^{\text {a }}$ Determined by GC analysis.

Table 3

Oxidation of an alcohol (Effect of solvents and catalyst loadings)

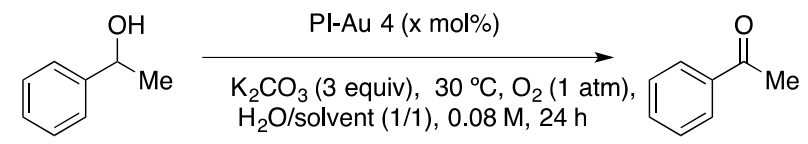

\begin{tabular}{|c|c|c|c|c|}
\hline Entry & PI-Au & Solvent & x & Yield (\%) $^{\mathrm{a}}$ \\
\hline 1 & $\mathbf{4 f}$ & DCM & 1 & 84 \\
\hline 2 & $\mathbf{4 f}$ & DCM & 3 & $>99$ \\
\hline 3 & reuse of entry 2 & DCM & 3 & $>99$ \\
\hline 4 & reuse of entry 3 & DCM & 3 & 99 \\
\hline 5 & $\mathbf{4 f}$ & toluene & 3 & 98 \\
\hline
\end{tabular}

\begin{tabular}{|c|c|c|c|c|}
\hline 6 & $\mathbf{4 f}$ & BTF & 3 & 99 \\
\hline 7 & $\mathbf{4 e}$ & BTF & 3 & 72 \\
\hline 8 & $\mathbf{4 d}$ & BTF & 3 & 58 \\
\hline 9 & $\mathbf{4 g}$ & BTF & 1 & 11 \\
\hline 10 & $\mathbf{4 h}$ & BTF & 1 & 17 \\
\hline 11 & $\mathbf{4 i}$ & BTF & 1 & 98 \\
\hline 12 & $\mathbf{4 j}$ & BTF & 1 & trace \\
\hline
\end{tabular}

${ }^{a}$ Determined by GC analysis.

Scheme 2. Preparation of PI-Au 4 (with second heating).

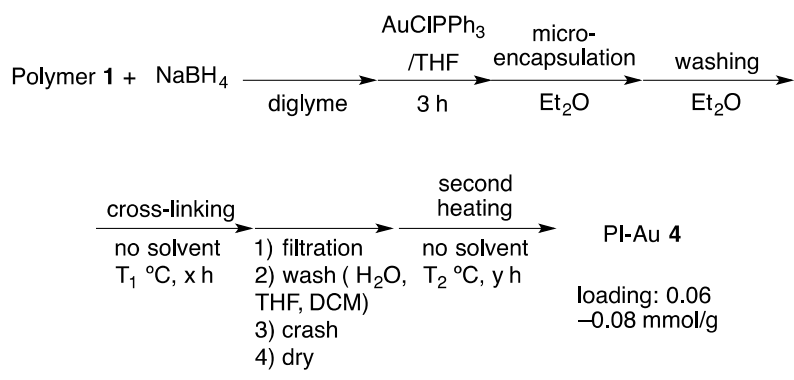

Table 4

Oxidation of an alcohol (Detailed optimization of catalyst preparation methods)

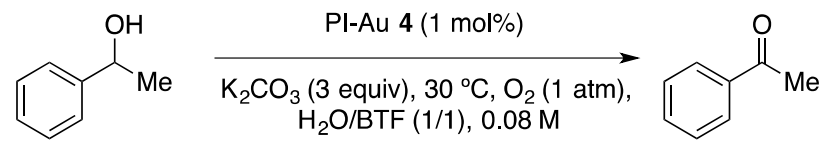

\begin{tabular}{|c|c|c|c|c|c|}
\hline Entry & $\mathrm{PI}-\mathrm{Au}$ & $\mathrm{T}_{1}, \mathrm{x}$ & $\mathrm{T}_{2,} \mathrm{y}$ & ${\text { Yield after } 3 \mathrm{~h}(\%)^{\mathrm{a}}}^{\mathrm{P}}$ & Yield after $5 \mathrm{~h} \mathrm{( \% )^{ \textrm {a } }} \mid$ \\
\hline 1 & $\mathbf{4 i}$ & 150,5 & - & 74 & - \\
\hline 2 & $\mathbf{4 k}$ & 120,5 & 170,5 & 93 & 98 \\
\hline 3 & $\mathbf{4 l}$ & 150,5 & 150,5 & $95^{\mathrm{b}}$ & $>99^{\mathrm{b}}, 88^{\mathrm{c}}$ \\
\hline 4 & $\mathbf{4 m}$ & 150,1 & 150,5 & 96 & 99 \\
\hline 5 & $\mathbf{4 n}$ & 150,5 & 150,1 & 94 & $>99$ \\
\hline 6 & $\mathbf{4 0}$ & 150,5 & 170,5 & 85 & 95 \\
\hline 7 & $\mathbf{4 p}$ & 150,5 & 200,5 & 61 & 99 \\
\hline
\end{tabular}

${ }^{a}$ Determined by GC analysis. ${ }^{b}$ Average using three lots of catalysts. ${ }^{\mathrm{c}}$ Reaction was performed under air (1 atm).

The first oxidation of silyl enol ethers to $\alpha$-hydroxyl ketone derivatives, using $m$-chlorobenzoic acid as a stoichiometric oxidant, was appeared in $1974 .{ }^{62-65}$ After these reports, various stoichiometric oxidants were applied to this transformation. ${ }^{66-70}$ Aerobic oxidation versions were also reported. ${ }^{71,72}$ For the reaction mechanism, it was proposed that silyl enol ethers were oxidized to siloxy epoxides and underwent 1,4-silyl rearrangement (Brook rearrangement) to afford $\alpha$-siloxyl ketones, followed by hydrolysis to $\alpha$-hydroxyl ketones (Scheme $3)^{73}$ Although various methods for the oxidation of silyl enol ethers were reported, there were no reports that metal nanocluster catalysts accelerated the aerobic oxidation of silyl enol ethers.

Scheme 3. Oxidation of silyl enol ethers.

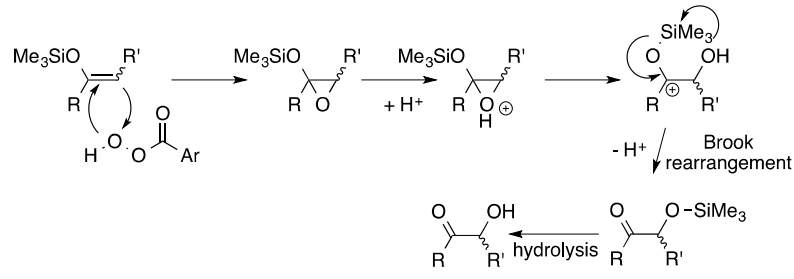


1-Phenyl-1-trimethylsiloxypropene was employed as a substrate, and the reaction conditions were optimized in the presence of $1 \mathrm{~mol} \%$ of PI-Au $4 \mathbf{l}$ in a toluene-water cosolvent system under air at $100{ }^{\circ} \mathrm{C}$ (Table 5). When PI-Au $4 \mathbf{l}$ with an $\mathrm{Au}$ loading of $0.0396-0.134 \mathrm{mmol} / \mathrm{g}$ was used, substantial hydrolysis to propiophenone occurred (entries 1-3, Figures 7-9). When PIAu $4 \mathbf{l}$ with an Au loading of $0.240 \mathrm{mmol} / \mathrm{g}$ was used, a mixture of $\alpha$-hydroxy ketone $5 \mathbf{a}$, diketone $\mathbf{5 b}$ and $\alpha$-siloxy ketone $\mathbf{5 f}$ was obtained, with trace amounts of $\alpha, \beta$-unsaturated ketone $5 \mathbf{d}$ and benzaldehyde 5e (entry 4, Figure 10). Hydrolysis of the silyl enol ether predominated using PI-Au $4 \mathbf{l}$ with an Au loading of $0.334 \mathrm{mmol} / \mathrm{g}$ (entry 5, Figure 11). When the reaction temperature was decreased, the reaction proceeded well at $>60$ ${ }^{\circ} \mathrm{C}$ (entries 6 and 10). The reaction became slow at $40{ }^{\circ} \mathrm{C}$ and room temperature (entries 11 and 12). The reaction at $80{ }^{\circ} \mathrm{C}$ gave the best result (entry 6). The catalyst loading did not greatly affect the reactivities (entries 6-8). The reaction did not proceed at all under the best reaction conditions in the absence of PI-Au (entry 9).

Table 5

Oxidation of a silyl enol ether (Initial optimization)

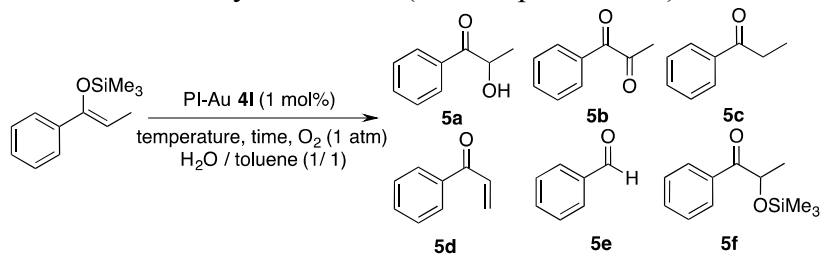

\begin{tabular}{|c|c|c|c|c|c|c|}
\hline Entry & $\begin{array}{c}\text { Au loading } \\
(\mathrm{mmol} / \mathrm{g})\end{array}$ & $\begin{array}{c}\text { Time } \\
(\mathrm{h})\end{array}$ & $\begin{array}{c}\text { Temp. } \\
\left({ }^{\circ} \mathrm{C}\right)\end{array}$ & $\begin{array}{c}\text { Conv. } \\
(\%)^{\mathrm{a}}\end{array}$ & $\begin{array}{c}\text { Sum of } \\
\mathbf{5 a}, \mathbf{5 b}, \\
\text { and 5f } \\
(\%)\end{array}$ & $\begin{array}{c}\text { Ratio (\%) } \\
\text { 5a:5b:5c:5d:5e:5f }\end{array}$ \\
\hline 1 & 0.040 & 14 & 100 & 89 & 2 & $0: 2: 82:-: 0:<1$ \\
\hline 2 & 0.072 & 14 & 100 & 96 & $<1$ & $0: 0: 89:-: 0:<1$ \\
\hline 3 & 0.134 & 20 & 100 & $>99$ & 3 & $1: 2: 57:-: 0: 0$ \\
\hline 4 & 0.240 & 16 & 100 & $>99$ & 36 & $16: 16: 30:+:<1: 4$ \\
\hline 5 & 0.334 & 11 & 100 & $>99$ & 10 & $5: 5: 62:-: 0: 0$ \\
\hline 6 & 0.240 & 11 & 80 & $>99$ & 39 & $5: 28: 25:+: 2: 6$ \\
\hline $7^{\mathrm{b}}$ & 0.240 & 18 & 80 & $>99$ & 36 & $14: 17: 30:-: 2: 5$ \\
\hline $8^{\mathrm{c}}$ & 0.240 & 18 & 80 & $>99$ & 34 & $17: 17: 22:-: 0: 0$ \\
\hline 9 & no catalyst & 16 & 80 & NR & NR & NR \\
\hline 10 & 0.240 & 15 & 60 & 98 & 33 & $7: 15: 25:+: 0: 11$ \\
\hline 11 & 0.240 & 111 & 40 & $>99$ & 31 & $14: 16: 31:-: 1: 1$ \\
\hline 12 & 0.240 & 111 & rt & 46 & 9 & $1: 4: 5:-: 0: 4$ \\
\hline
\end{tabular}

${ }^{\mathrm{a}}$ Determined by GC analysis. +: trace; -: Not detected. ${ }^{\mathrm{b}}$ Used 0.5 mol\% of PI Au 4l. ${ }^{\mathrm{c}}$ Used 2 mol\% of PI Au 4l. NR: no reaction.

Next, the solvent system was optimized (Table 6). In pure water, the total amount of oxidized products $(\mathbf{5 a}, \mathbf{5 b}, \mathbf{5 f})$ decreased slightly, and no siloxy ketone $\mathbf{5 f}$ was obtained because of smooth hydrolysis (entry 1). The ratio of water to toluene was varied (entries 2-4). When a mixture of toluene and water was used, the total amounts of the oxidized products were almost the same; however, more siloxy ketone was obtained with less water. In pure toluene, the reaction hardly proceeded (entry 5). Cosolvent systems of hydrophobic organic solvents and water gave comparable yields of the oxidized products (entries 6-13). In particular, a 1:1 mixture of chlorobenzene and water gave the best result (entry 8). On the other hand, the reaction hardly proceeded in the presence of water-miscible organic solvents, such as DMF and DMSO (entries 14-17). The reaction proceeded well in the presence of $10 \mathrm{~mol} \%$ of azobisisobutyronitrile (AIBN) (entry 18). On the other hand, the oxidation reaction hardly proceeded, and propiophenone $5 \mathrm{c}$ was the major product in the presence of $(2,2,6,6-$ Tetramethylpiperidin-1-yl)oxy (TEMPO), which is known as a radical inhibitor (entry 19). These results indicate that this reaction proceeds via a radical intermediate.

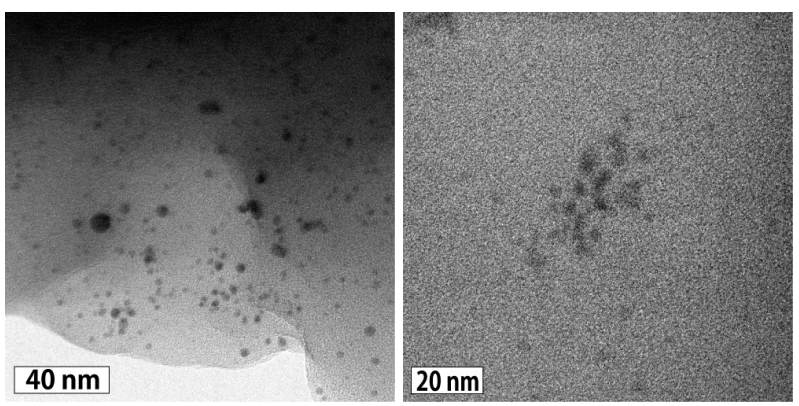

Fig. 7. Typical TEM images of PI-Au 41 (Au loading: $0.040 \mathrm{mmol} / \mathrm{g}$ ).
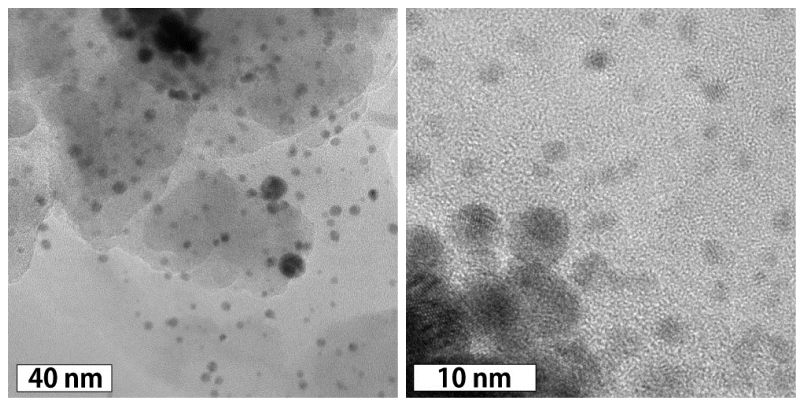

Fig. 8. Typical TEM images of PI-Au 41 (Au loading: $0.072 \mathrm{mmol} / \mathrm{g}$ ).

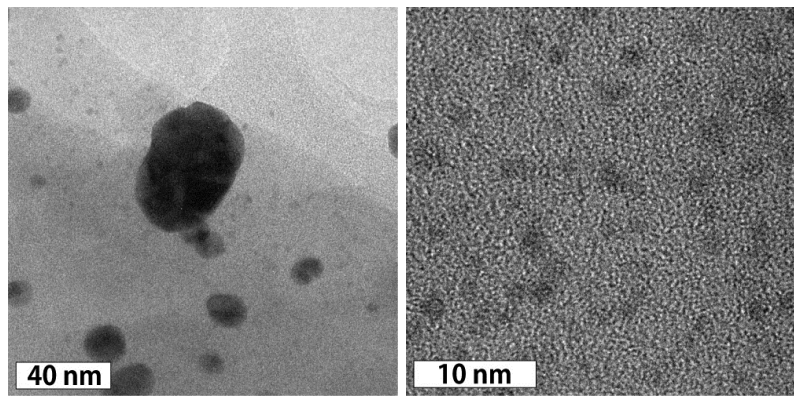

Fig. 9. Typical TEM images of PI-Au 41 (Au loading: $0.143 \mathrm{mmol} / \mathrm{g}$ ).
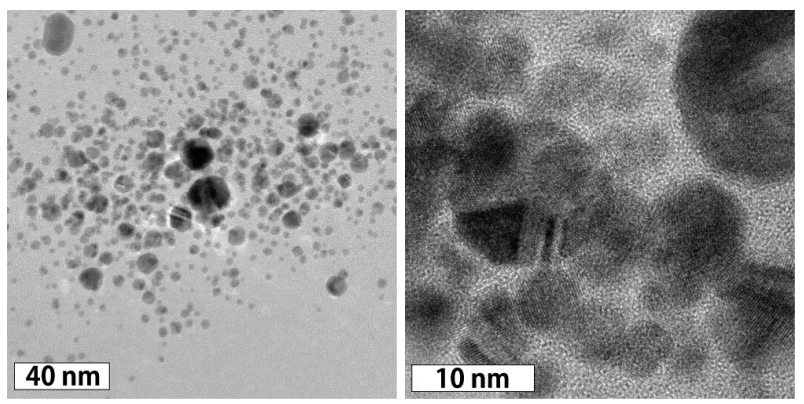

Fig. 10. Typical TEM images of PI-Au 41 (Au loading: 0.240 mmol/g). 


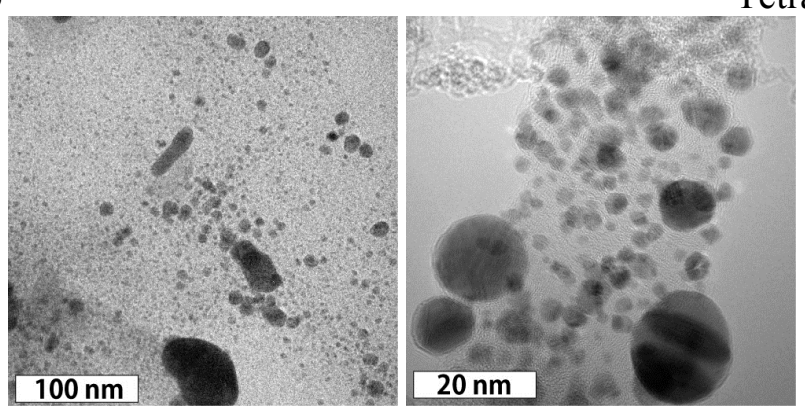

Fig. 11. Typical TEM images of PI-Au $4 \mathbf{l}$ (Au loading: $0.334 \mathrm{mmol} / \mathrm{g}$ ).

Table 6

Oxidation of a silyl enol ether (Effect of solvents and additives)

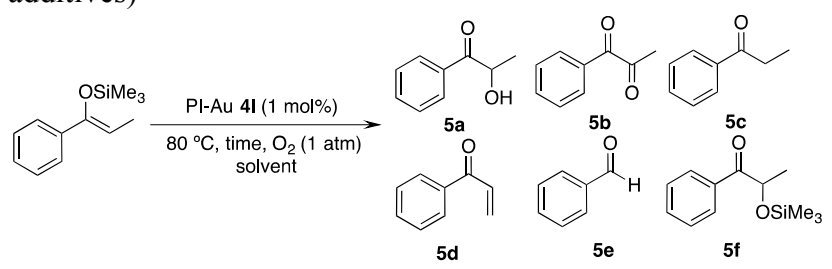

\begin{tabular}{|c|c|c|c|c|c|}
\hline Entry & Solvent & $\begin{array}{l}\text { Time } \\
(\mathrm{h})\end{array}$ & $\begin{array}{l}\text { Conv. } \\
(\%)^{\mathrm{a}}\end{array}$ & $\begin{array}{c}\text { Sum of } \mathbf{5 a}, \\
\mathbf{5 b}, \text { and } \mathbf{5 f} \\
(\%)\end{array}$ & $\begin{array}{c}\text { Ratio (\%) } \\
\text { 5a:5b:5c:5d:5e:5 } \\
\text { f }\end{array}$ \\
\hline 1 & $\mathrm{H}_{2} \mathrm{O} 2 \mathrm{~mL}$ & 15 & $>99$ & 25 & $10: 15: 7:-: 0: 0$ \\
\hline 2 & $\begin{array}{c}\text { toluene } 1 \mathrm{~mL} / \mathrm{H}_{2} \mathrm{O} \\
1 \mathrm{~mL}\end{array}$ & 11 & $>99$ & 39 & $5: 28: 25:+: 2: 6$ \\
\hline 3 & $\begin{array}{c}\text { toluene } 0.5 \mathrm{~mL} / \\
\mathrm{H}_{2} \mathrm{O} 1.5 \mathrm{~mL}\end{array}$ & 15 & $>99$ & 40 & $18: 20: 19:+: 0: 2$ \\
\hline 4 & $\begin{array}{c}\text { toluene } 1.5 \mathrm{~mL} / \\
\mathrm{H}_{2} \mathrm{O} 0.5 \mathrm{~mL}\end{array}$ & 15 & $>99$ & 41 & $9: 19: 20:+: 2: 12$ \\
\hline 5 & toluene $2 \mathrm{~mL}$ & 15 & 17 & 7 & $0: 0: 7:+: 0: 7$ \\
\hline 6 & $\begin{array}{c}\text { decane } 1 \mathrm{~mL} / \mathrm{H}_{2} \mathrm{O} \\
1 \mathrm{~mL}\end{array}$ & 12 & 83 & 28 & $6: 17: 20:-: 0: 5$ \\
\hline 7 & $\begin{array}{l}\text { Decalin } 1 \mathrm{~mL} / \mathrm{H}_{2} \mathrm{O} \\
1 \mathrm{~mL}\end{array}$ & 12 & 98 & 39 & $18: 18: 15:-: 0: 3$ \\
\hline 8 & $\begin{array}{l}\text { Chlorobenzene } 1 \\
\mathrm{~mL} / \mathrm{H}_{2} \mathrm{O} 1 \mathrm{~mL}\end{array}$ & 12 & $>99$ & 45 & $13: 24: 16:+: 0: 8$ \\
\hline 9 & $\begin{array}{l}\text { chlorobenzene } 0.5 \\
\mathrm{~mL} / \mathrm{H}_{2} \mathrm{O} 1.5 \mathrm{~mL}\end{array}$ & 14 & $>99$ & 32 & $15: 16: 35:+: 0: 1$ \\
\hline 10 & $\begin{array}{l}\text { chlorobenzene } 1.5 \\
\mathrm{~mL} / \mathrm{H}_{2} \mathrm{O} 0.5 \mathrm{~mL}\end{array}$ & 14 & $>99$ & 42 & $11: 21: 21:+: 0: 10$ \\
\hline 11 & $\begin{array}{c}\mathrm{C}_{2} \mathrm{H}_{4} \mathrm{Cl}_{2} 1 \mathrm{~mL} / \mathrm{H}_{2} \mathrm{O} \\
1 \mathrm{~mL}\end{array}$ & 14 & $>99$ & 28 & 7:14:28:-:0:7 \\
\hline 12 & $\begin{array}{c}\text { isodurene } 1 \mathrm{~mL} / \\
\mathrm{H}_{2} \mathrm{O} 1 \mathrm{~mL}\end{array}$ & 14 & $>99$ & 34 & $16: 17: 25:-: 4: 1$ \\
\hline 13 & $\begin{array}{c}\text { mesitylene } 1 \mathrm{~mL} / \\
\mathrm{H}_{2} \mathrm{O} 1 \mathrm{~mL}\end{array}$ & 14 & $>99$ & 33 & 11:18:22:-:0:4 \\
\hline 14 & DMF $2 \mathrm{~mL}$ & 12 & $>99$ & 14 & 2:12:27:-:0:0 \\
\hline 15 & $\begin{array}{l}\text { DMF } 1 \mathrm{~mL} / \mathrm{H}_{2} \mathrm{O} \\
\quad 1 \mathrm{~mL}\end{array}$ & 14 & $>99$ & 3 & 1:2:18:-:0:0 \\
\hline 16 & $\begin{array}{c}\text { DMF } 1 \mathrm{~mL} / \text { toluene } \\
1 \mathrm{~mL}\end{array}$ & 14 & $>99$ & 8 & $0: 8: 82:-: 0: 0$ \\
\hline 17 & $\begin{array}{l}\text { DMSO } 1 \mathrm{~mL} / \\
\text { toluene } 1 \mathrm{~mL} \\
\text { toluene } 1 \mathrm{~mL} /\end{array}$ & 14 & $>99$ & 2 & 0:1:91:-:0:1 \\
\hline 18 & $\begin{array}{c}\mathrm{H}_{2} \mathrm{O} 1 \mathrm{~mL}+\mathrm{AIBN} \\
(10 \mathrm{~mol} \%) \\
\text { toluene } 1 \mathrm{~mL} /\end{array}$ & 13 & 94 & 54 & $30: 14: 5:-: 5: 10$ \\
\hline 19 & $\begin{array}{c}\mathrm{H}_{2} \mathrm{O} 1 \mathrm{~mL}+ \\
\text { TEMPO } \\
(10 \mathrm{~mol} \%) \\
\end{array}$ & 13 & $>99$ & 6 & $0: 2: 89:-: 5: 4$ \\
\hline
\end{tabular}

${ }^{a}$ Determined by GC analysis.
Tetrahedron

Table 7

Control experiments

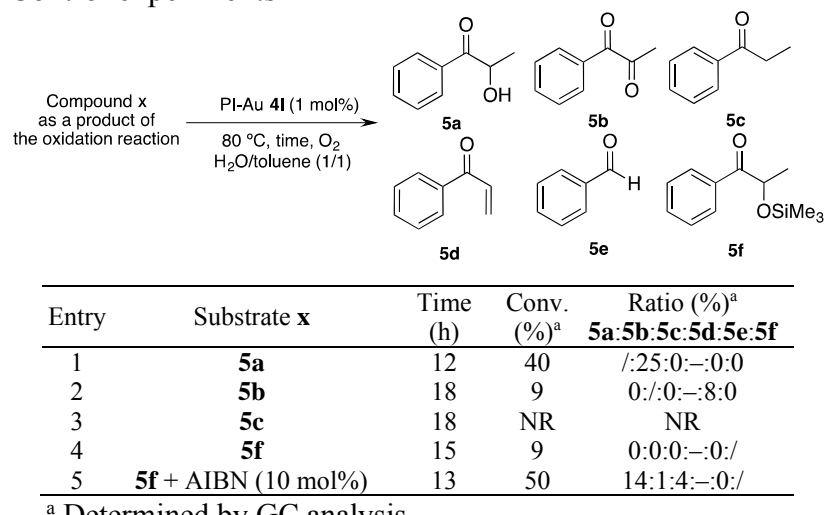

To determine the reaction pathways affording each oxidized product from the silyl enol ether, we conducted control experiments using each oxidized compound as a substrate (Table 7). When hydroxy ketone 5a was used as a substrate, only the diketone was obtained via aerobic oxidation of the alcohol catalyzed by PI-Au $\mathbf{4 l}$ (entry 1 ). Diketone $5 \mathbf{b}$ could be converted to a very small amount of benzaldehyde via oxidative $\mathrm{C}-\mathrm{C}$ bond cleavage (entry 2). Propiophenone, which is a hydrolyzed compound of the silyl enol ether, could not be oxidized at all (entry 3). The $\alpha$-siloxy ketone could not be converted to the $\alpha$ hydroxy ketone only in the presence of PI-Au $4 \mathbf{l}$ (entry 4), but hydrolysis proceeded when AIBN was added (entry 5). Based on these results, we summarized the reaction pathway in the aerobic oxidation of silyl enol ether in the presence of PI-Au $4 \mathbf{l}$ (Scheme 4). Because PI-Au $4 \mathbf{l}$ is an active catalyst toward the aerobic oxidation of alcohols, the reaction does not stop at the $\alpha$-hydroxy ketone; it results in a variety of oxidized products such as diketone $5 \mathbf{b}$ and benzaldehyde 5e. Surprisingly, hydrolysis of the $\alpha$-siloxy ketone hardly proceeded under the standard reaction conditions but partially proceeded in the presence of a radical initiator. When the reactions start from a silyl enol ether, some radical intermediates form with molecular oxygen, and they might partially enhance the hydrolysis of the $\alpha$-siloxy ketone. However, this might not be a major pathway that gives the $\alpha$ hydroxy ketone. These results indicate that the $\alpha$-hydroxy ketone and the diketone, which are the major products in most cases, are produced directly from the silyl enol ether in the presence of PI$\mathrm{Au}$ 4l, not via the intermediate of $\alpha$-siloxy ketone $5 \mathbf{f}$. Furthermore, the reaction mechanism involving catalysis by PI$\mathrm{Au} \mathbf{4 l}$ is quite different from the traditional Rubottom oxidation that includes Brook rearrangement (Scheme 3).

Scheme 4. Reaction pathways in the aerobic oxidation of silyl enol ether in the presence of PI-Au 41.

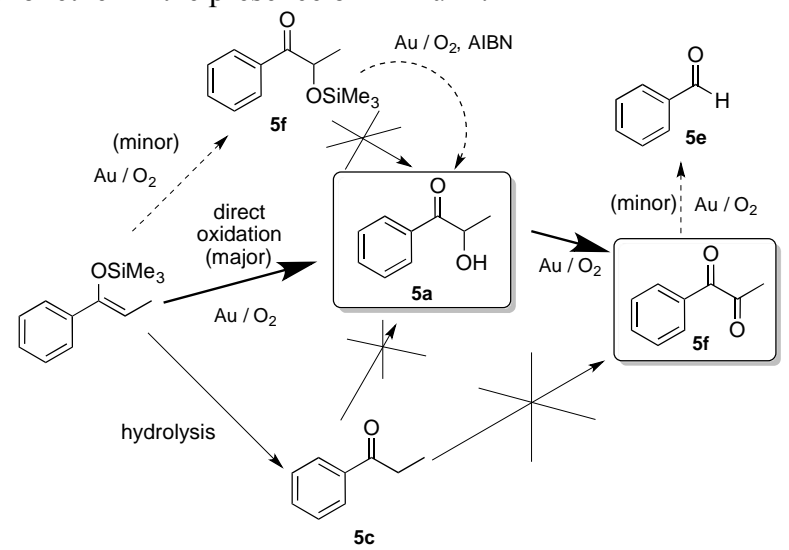




\section{Conclusion}

In summary, we have developed polymer-incarcerated $\mathrm{Au}$ nanocluster catalysts as versatile heterogeneous aerobic oxidation catalysts based on our original immobilization methods; namely, microencapsulation and polymer incarceration using polystyrene derivatives with cross-linking moieties as organic supports. The catalysts thus developed were successfully applied to the aerobic oxidation of alcohol, homo-coupling of phenyl boronic acid, and Rubottom-type oxidation of silyl enol ether. Choice of polymer structures, Au sources, and the combination of solvents during nanocluster formation, stabilization and microencapsulation are keys to the fabrication of active $\mathrm{Au}$ nanocluster catalysts. In addition, nanocluster size and its distribution are very sensitive to Au loading. The best loading of catalysts was found to be dependent on the target reactions: lower loading catalysts are better in the case of alcohol oxidation and phenyl boronic acid homo-coupling, whereas relatively higher loading catalysts are better in the case of oxidation of silyl enol ether. Further investigations into the discovery of new catalytic activity of PI$\mathrm{Au}$ and more detailed structure analyses of these Au nanocluster catalysts are ongoing.

\section{Experimental}

\subsection{General}

\subsubsection{Chromatography}

Reactions were monitored with analytical thin-layer TLC on silica gel $60 \mathrm{~F}_{254}$ plates and visualized under UV $(254 \mathrm{~nm})$ and/or by staining. Column chromatography was performed on silica gel 60 (Merck), and preparative TLC was carried out by using Wakogel B-5F (Wako Pure Chemical Industry).

\subsubsection{NMR measurements}

NMR spectra were recorded with JEOL JMN-LA400, 500 or 600 spectrometers. Chemical shifts are given in parts per million, referenced to the solvent peak of $\mathrm{CDCl}_{3}$, defined at 77.2 ppm $\left({ }^{13} \mathrm{C} \mathrm{NMR}\right)$ and $7.24 \mathrm{ppm}\left({ }^{1} \mathrm{H} \mathrm{NMR}\right)$.

The structures of known compounds were confirmed by comparison with commercially available compounds or data available in the literature.

\subsubsection{ICP analyses}

Inductively coupled plasma-atomic emission spectrometry (ICP-AES) analysis was performed on a Shimadzu ICPS-7510 instrument.

\subsubsection{Mass spectrometry}

High-resolution mass spectra were recorded using a Bruker Daltonics BioTOF II mass spectrometer (ESI) and a JEOL JMST100TD AccuTOF TLC (DART).

\subsubsection{Reagents}

Commercially available reagents and solvents were purchased from Tokyo Kasei Kogyo Co., Sigma-Aldrich, Wako Pure Chemical Industries, Kanto Chemical Co., or Strem Chemicals and then used after purification based on standard procedures, as necessary. $\mathrm{NaBH}_{4}$ was purchased from Wako Pure Chemical Industries. It was recrystallized from freshly distilled diglyme by heating (according to a literature procedure) and stored in a glove box. ${ }^{74}$ During recrystallization, it is important to carry out all operations under an Ar atmosphere. The activity of the catalysts and reproducibility are highly influenced by the purity and the condition of $\mathrm{NaBH}_{4}$ during catalyst preparation.

\subsubsection{GC and TEM analyses}

For alcohol oxidation, GC analysis was performed on a Shimadzu GC-17A apparatus (column = GL Science TCWAX; gas pressure: $158 \mathrm{kPa}$, total flow: $58 \mathrm{~mL} / \mathrm{min}$, column flow: 1.6 $\mathrm{mL} / \mathrm{min}$, linear velocity: $32 \mathrm{~cm} / \mathrm{s}$, sprit ratio: 32 , injection temperature: $250{ }^{\circ} \mathrm{C}$, detector temperature: $250{ }^{\circ} \mathrm{C}$ ). For the oxidation of silyl enol ethers and their derivatives, GC analysis was performed on a Shimadzu GC-2010 apparatus (column = GL Science, TCWAX, $0.25 \mathrm{~mm}$ ID, $0.25 \mu \mathrm{m}, 60.0 \mathrm{~m}$; gas pressure: $214.2 \mathrm{kPa}$, total flow: $90.6 \mathrm{~mL} / \mathrm{min}$, column flow: $1.86 \mathrm{~mL} / \mathrm{min}$, linear velocity: $30.8 \mathrm{~cm} / \mathrm{sec}$, purge flow: $3.0 \mathrm{~mL} / \mathrm{min}$, sprit ratio: 46.0, injection temperature: $250{ }^{\circ} \mathrm{C}$, FID: $250{ }^{\circ} \mathrm{C}$; column program: starting from $100.0^{\circ} \mathrm{C}, 10 \mathrm{~min}$ hold, $10{ }^{\circ} \mathrm{C} / \mathrm{min}$ to 220 ${ }^{\circ} \mathrm{C}, 10 \mathrm{~min}$ hold). For all other compounds, $\mathrm{GC}$ analysis was performed on a Shimadzu GC-2010 apparatus (column $=\mathrm{J} \& \mathrm{~W}$ Scientific DB-1; gas pressure: $157.5 \mathrm{kPa}$, total flow: 41.3 $\mathrm{mL} / \mathrm{min}$, column flow: $0.93 \mathrm{~mL} / \mathrm{min}$, linear velocity: $21.1 \mathrm{~cm} / \mathrm{s}$, sprit ratio: 40.1 , injection temperature: $300{ }^{\circ} \mathrm{C}$, detector temperature: $300{ }^{\circ} \mathrm{C}$ ).

Transmission electron microscopy (TEM) images were obtained using a JEOL JEM-1010 instrument operated at $80 \mathrm{kV}$ or a JEOL JEM-2100F instrument operated at $200 \mathrm{kV}$. A 10-20 mg sample of solid catalyst was ground in a pestle and mortar together with a few milliliters of methanol. After waiting about $10 \mathrm{~s}$ for most of the sample to settle, the supernatant, which contained minute amounts of the sample, was transferred by pipette. A drop of the solution was placed on a carbon-coated $\mathrm{Cu}$ grid and allowed to dry in air (without staining).

\subsection{Preparation of monomers}

4.2.1. Preparation of 2-(2-(2-(2-(4vinylbenzyloxy)ethoxy)ethoxy)ethoxy)ethanol: ${ }^{39}$

To sodium hydride ( $60 \%$ in mineral oil, $3.34 \mathrm{~g}, 83.54 \mathrm{mmol}$, 1.50 equiv) suspended in THF $(150 \mathrm{~mL})$, tetraethylene glycol (14.4 mL, $83.54 \mathrm{mmol}, 1.50$ equiv) was added at $0{ }^{\circ} \mathrm{C}$. After the reaction mixture was stirred for $1 \mathrm{~h}$ at room temperature, 1(chloromethyl)-4-vinylbenzene ( $7.9 \mathrm{~mL}, 55.69 \mathrm{mmol}, 1$ equiv) was added, and the mixture was stirred for a further $12 \mathrm{~h}$. The mixture was diluted with ethyl acetate $(200 \mathrm{~mL})$. Saturated aqueous ammonium chloride $(140 \mathrm{~mL})$ was added to quench the reaction, and the aqueous layer was extracted with ethyl acetate $(3 \times 100 \mathrm{~mL})$. The combined organic layers were dried over sodium sulfate, and the solvent was removed in vacuo. The residue was purified by flash chromatography to afford (2-(2-(2(4-vinylbenzyloxy)ethoxy)ethoxy)ethoxy)ethanol ether (13.7 g, $78 \%$ ). ${ }^{1} \mathrm{H}$ NMR $\left(500 \mathrm{MHz}, \mathrm{CDCl}_{3}, 20{ }^{\circ} \mathrm{C}\right.$ ): $\delta$ (ppm) 2.55-2.59 $(\mathrm{m}, 1 \mathrm{H}), 3.59-3.73(\mathrm{~m}, 16 \mathrm{H}), 4.55(\mathrm{~s}, 2 \mathrm{H}), 5.25(\mathrm{~d}, 1 \mathrm{H}, \mathrm{J}=6.4$ $\mathrm{Hz}), 5.53(\mathrm{~d}, 1 \mathrm{H}, \mathrm{J}=18 \mathrm{~Hz}), 6.71(\mathrm{dd}, 1 \mathrm{H}, \mathrm{J}=11.0,17.9 \mathrm{~Hz})$, 7.22-7.27 (m, 3H), 7.31-7.39 (m, 2H); ${ }^{13} \mathrm{C}$ NMR (150 MHz, $\mathrm{CDCl}_{3}, 20^{\circ} \mathrm{C}$ ): $\delta$ (ppm) 61.8, 69.5, 70.5, 70.69, 70.74, 72.6, 73.0, 113.8, 126.3, 128.0, 136.0, 137.1, 138.0.

4.2.2. Preparation of 4-vinylbenzyl glycidyl ether: ${ }^{38}$

To sodium hydride (60\% in mineral oil, $13.1 \mathrm{~g}, 327.60 \mathrm{mmol}$, 2.00 equiv) suspended in DMF $(300 \mathrm{~mL})$, glycidol $(27.15 \mathrm{~mL}$, $459.1 \mathrm{mmol}, 2.50$ equiv) and 1-(chloromethyl)-4-vinylbenzene ( $23.3 \mathrm{~mL}, 163.80 \mathrm{mmol}, 1.00$ equiv) were added at $0{ }^{\circ} \mathrm{C}$. After the reaction mixture was stirred for $4 \mathrm{~h}$, the mixture was diluted with ethyl acetate $(400 \mathrm{~mL})$. Saturated aqueous ammonium chloride $(200 \mathrm{~mL})$ was added to quench the reaction, and the aqueous layer was extracted with ethyl acetate $(3 \times 100 \mathrm{~mL})$. The combined organic layers were dried over sodium sulfate, and the solvent was removed in vacuo. The residue was purified by flash chromatography to afford 4-vinylbenzyl glycidyl ether (23 g, 74\%). ${ }^{1} \mathrm{H}$ NMR $\left(500 \mathrm{MHz}, \mathrm{CDCl}_{3}, 20{ }^{\circ} \mathrm{C}\right): \delta(\mathrm{ppm}) 2.60(\mathrm{dd}$, $1 \mathrm{H}, \mathrm{J}=2.8,4.8 \mathrm{~Hz}), 2.78(\mathrm{dd}, 1 \mathrm{H}, \mathrm{J}=4.0,4.8 \mathrm{~Hz}), 3.17(\mathrm{~m}, 1 \mathrm{H})$, 
$3.42(\mathrm{dd}, 1 \mathrm{H}, \mathrm{J}=5.6,11.2 \mathrm{~Hz}), 3.74(\mathrm{dd}, 1 \mathrm{H}, \mathrm{J}=2.8,11.2 \mathrm{~Hz})$, $4.56(\mathrm{dd}, 2 \mathrm{H}, \mathrm{J}=10.8,17.6 \mathrm{~Hz}), 7.30(\mathrm{~d}, 2 \mathrm{H}, \mathrm{J}=8.0 \mathrm{~Hz}), 7.39(\mathrm{~d}$, $2 \mathrm{H}, \mathrm{J}=8.0 \mathrm{~Hz}) ;{ }^{13} \mathrm{C} \mathrm{NMR}\left(150 \mathrm{MHz}, \mathrm{CDCl}_{3}, 20{ }^{\circ} \mathrm{C}\right): \delta(\mathrm{ppm})$ $40.2,50.7,70.7,72.9,113.8,126.2,127.9,136.4,137.0,137.4$.

\subsubsection{1-(4-vinylbenzyl)-2-pyrrolidinone: ${ }^{75}$}

To sodium hydride (60\% in mineral oil, $4.8 \mathrm{~g})$ suspended in dry DMF $(75 \mathrm{~mL})$ was added 2-pyrrolidinone $(8.6 \mathrm{~g})$ in DMF $(25$ $\mathrm{mL})$ at $0{ }^{\circ} \mathrm{C}$. A solution of 1-(chloromethyl)-4-vinylbenzene $(17.0 \mathrm{~g})$ in DMF $(15 \mathrm{~mL})$ was added at the same temperature, and then the mixture was stirred for $24 \mathrm{~h}$ at room temperature. The mixture was cooled to $0{ }^{\circ} \mathrm{C}$ and diluted with diethyl ether. Saturated aqueous ammonium chloride was added to quench the reaction, and the aqueous layer was extracted with diethyl ether. The combined organic layers were dried over sodium sulfate, and the solvent was removed in vacuo. The residue was purified by flash chromatography (silica gel, hexane/EtOAc) to afford 1-(4vinylbenzyl)-2-pyrrolidinone (15.9 g, 79\%). ${ }^{1} \mathrm{H}$ NMR $\left(\mathrm{CDCl}_{3}\right) \delta$ 1.93-2.04 (m, 2H), $2.43(\mathrm{t}, 2 \mathrm{H}, J=8.0 \mathrm{~Hz}), 5.23(\mathrm{~d}, 10.8 \mathrm{~Hz}$, $1 \mathrm{H}), 5.73(\mathrm{~d}, 1 \mathrm{H}, J=11.2) 5.8,11.5 \mathrm{~Hz}), 6.69(\mathrm{dd}, 1 \mathrm{H}, J=11.0$, 17.6 Hz), 7.14-7.21 (m, 2H), 7.32-7.37 (m, 2H); ${ }^{13} \mathrm{C}$ NMR $\left(\mathrm{CDCl}_{3}\right) \delta 17.7,30.9,46.3,46.6,114.0,126.5128 .4,136.2$, $136.3,136.9,174.9$.

\subsubsection{3-Bromo-2-phenylpropene: ${ }^{24}$}

A mixture of 2-phenylpropene $(22.4 \mathrm{~g}, 190 \mathrm{mmol}), \mathrm{N}-$ bromosuccinimide $(23.7 \mathrm{~g}, 133 \mathrm{mmol})$ and bromobenzene (76 $\mathrm{mL}$ ) was rapidly heated at $160{ }^{\circ} \mathrm{C}$ (bath temperature) until the $\mathrm{N}$ bromosuccinimide was dissolved. After cooling to room temperature, the precipitate was removed by filtration and washed with chloroform. The filtrate was purified by distillation (bp $80-85{ }^{\circ} \mathrm{C} / 3 \mathrm{~mm} \mathrm{Hg}$ ) to afford 3-bromo-2-phenylpropene containing 1-bromo-2-phenylpropene $(15.5 \mathrm{~g})$. The purity was found to be $78.0 \%$ (determined by ${ }^{1} \mathrm{H}$ NMR). ${ }^{1} \mathrm{H}$ NMR $\left(\mathrm{CDCl}_{3}\right)$ $\delta 4.39(\mathrm{~s}, 2 \mathrm{H}), 5.49(\mathrm{~s}, 1 \mathrm{H}), 5.56(\mathrm{~s}, 1 \mathrm{H}), 7.33-7.51(\mathrm{~m}, 5 \mathrm{H}) ;{ }^{13} \mathrm{C}$ NMR $\left(\mathrm{CDCl}_{3}\right) \delta 34.2,117.2,126.1,128.3,128.5,137.6,144.2$.

\subsubsection{2-[(2-Phenylallyloxy)methyl]oxirane: ${ }^{32}$}

To sodium hydride $(60 \%$ in mineral oil, $1.6 \mathrm{~g}, 40 \mathrm{mmol})$ suspended in dry DMF $(75 \mathrm{~mL})$ was added glycidol $(7.4 \mathrm{~g}, 100$ $\mathrm{mmol})$ in DMF $(5 \mathrm{~mL})$ at $0{ }^{\circ} \mathrm{C}$. Then a solution of 3-bromo-2phenylpropene (78\% purity, $5.05 \mathrm{~g}, 20 \mathrm{mmol})$ in DMF $(10 \mathrm{~mL})$ was added at the same temperature, and the mixture was stirred for $24 \mathrm{~h}$ at room temperature. After the mixture was cooled to 0 ${ }^{\circ} \mathrm{C}$ and diluted with diethyl ether, saturated aqueous ammonium chloride was added to quench the reaction, and the aqueous layer was extracted with diethyl ether. The combined organic layers were dried over sodium sulfate, and the solvent was removed in vacuo. The residue was purified by flash chromatography (silica, hexane/EtOAc) to afford 2-[(2-phenylallyloxy)methyl]oxirane (2.66 g, 70\%). ${ }^{1} \mathrm{H}$ NMR $\left(\mathrm{CDCl}_{3}\right) \delta 2.59(\mathrm{dd}, 1 \mathrm{H}, J=2.7,5.1$ $\mathrm{Hz}), 2.78$ (dd, $1 \mathrm{H}, J=4.2,5.1 \mathrm{~Hz}), 3.13-3.17$ (m, $1 \mathrm{H}), 3.46$ (dd, $1 \mathrm{H}, J=5.8,11.5 \mathrm{~Hz}), 3.77(\mathrm{dd}, 1 \mathrm{H}, J=3.2,11.5 \mathrm{~Hz}), 4.41$ (ddd, $1 \mathrm{H}, J=0.7,1.2,12.9 \mathrm{~Hz}), 4.48(\mathrm{ddd}, 1 \mathrm{H}, J=0.5,1.2,12.9 \mathrm{~Hz})$, $5.34-5.36(\mathrm{~m}, 1 \mathrm{H}), 5.53-5.54(\mathrm{~m}, 1 \mathrm{H}), 7.45-7.48(\mathrm{~m}, 5 \mathrm{H}) ;{ }^{13} \mathrm{C}$ NMR $\left(\mathrm{CDCl}_{3}\right) \delta 44.3,50.8,70.5,73.2,114.6,126.0,127.8$, 128.4, 138.6, 143.9; IR (KBr) 3000, 2924, 2867, 1911, 1812, 1701, 1630, 1512, 1479, 1407, 1337, 1254, 1205, 1107, 991, 909, $839 \mathrm{~cm}^{-1}$; HRMS (ESI) calcd for $\mathrm{C}_{13} \mathrm{H}_{16} \mathrm{O}_{2}\left(\mathrm{M}^{+}\right)$: 190.0994, found: 190.0998 .

\subsubsection{Preparation of tetraethylene glycol mono-2-} phenyl-2-propenyl ether: ${ }^{32}$

To sodium hydride ( $60 \%$ in mineral oil, $1.82 \mathrm{~g}, 45.4 \mathrm{mmol})$ suspended in THF $(70 \mathrm{~mL})$ was added tetraethylene glycol $(8.81$ $\mathrm{mL}, 45.4 \mathrm{mmol}$ ) at $0{ }^{\circ} \mathrm{C}$. The reaction mixture was stirred for $1 \mathrm{~h}$ at room temperature. 3-Bromo-2-phenylpropene (3.46 g, 22.7 mmol) was added, and the mixture was stirred for a further $12 \mathrm{~h}$. The mixture was then cooled to $0{ }^{\circ} \mathrm{C}$ and diluted with diethyl ether, saturated aqueous ammonium chloride was added to quench the reaction, and the aqueous layer was extracted with diethyl ether. The combined organic layers were dried over sodium sulfate, and the solvent was removed in vacuo. The residue was purified by flash chromatography to afford tetraethylene glycol mono-2-phenyl-2-propenyl ether (4.52 g, $64 \%$ ) and tetraethylene glycol di-2-phenyl-2-propenyl ether (621 $\mathrm{mg}, 13 \%)$.

4.2.6.1. Tetraethyleneglycol mono-2-phenyl-2propenyl ether ${ }^{32}$ :

${ }^{1} \mathrm{H}$ NMR $\left(\mathrm{CDCl}_{3}\right) \delta 2.72(\mathrm{~s}, 1 \mathrm{H}), 3.58-3.74(\mathrm{~m}, 16 \mathrm{H}), 4.42(\mathrm{~s}$, $2 \mathrm{H}), 5.34(\mathrm{~d}, 1 \mathrm{H}, J=1.2 \mathrm{~Hz}), 5.53(\mathrm{~d}, 1 \mathrm{H}, J=0.5 \mathrm{~Hz}), 7.25-7.36$ $(\mathrm{m}, 3 \mathrm{H}), 7.44-7.52(\mathrm{~m}, 2 \mathrm{H}) ;{ }^{13} \mathrm{C}$ NMR $\delta 61.7,69.2,70.3,70.53$, 70.58, 72.4, 73.1, 114.4, 126.1, 127.7, 128.3, 138.7, 144.0.

4.2.6.2. Tetraethyleneglycol di-2-phenyl-2-propenyl ether ${ }^{32}$ :

${ }^{1} \mathrm{H}$ NMR $\left(\mathrm{CDCl}_{3}\right) \delta 3.55-3.75(\mathrm{~m}, 16 \mathrm{H}), 4.41(\mathrm{~s}, 4 \mathrm{H}), 5.33(\mathrm{~d}$, $2 \mathrm{H}, J=1.0 \mathrm{~Hz}), 5.51(\mathrm{~s}, 2 \mathrm{H}), 7.23-7.36(\mathrm{~m}, 6 \mathrm{H}), 7.43-7.50(\mathrm{~m}$, $4 \mathrm{H}) ;{ }^{13} \mathrm{C}$ NMR $\delta 69.2,70.47,70.51,73.0,114.3,126.0,127.6$, $128.2,138.7,144.0$.

\subsection{Preparation of polymers}

\subsubsection{Preparation of copolymer 1:}

Styrene (3 g, $28.80 \mathrm{mmol}, 1.00$ equiv), 4-vinylbenzyl glycidyl ether $(5.50 \mathrm{~g}, 28.80 \mathrm{mmol}, 1.00$ equiv $), 2-(2-(2-(2-(4-$ vinylbenzyloxy)ethoxy)ethoxy)ethoxy)ethanol (8.95 g, 28.80 mmol, 1.00 equiv) and 2,2'-azobis(4-methoxy)-2,4dimethylvaleronitrile ( $242 \mathrm{mg}, 0.864 \mathrm{mmol}, 0.30$ equiv) were combined in chloroform $(16.0 \mathrm{~mL})$. The mixture was stirred for $72 \mathrm{~h}$ at room temperature. The resulting polymer solution was slowly poured into diethyl ether. The solvent was removed by decantation, and the residue was dissolved in THF. The polymer solution was slowly poured into diethyl ether again. The same procedure was repeated a total of three times. The precipitated polymer was filtered, washed several times with diethyl ether and then dried in vacuo to afford the desired copolymer $(\mathbf{1}, 10.52 \mathrm{~g}$, $63 \%$ yield). The molar ratio of the components was determined by ${ }^{1} \mathrm{H}$ NMR analysis (x:y:z $\left.=34: 32: 34\right)$.

\subsubsection{Preparation of copolymer 2:}

1-(4-vinylbenzyl)-2-pyrrolidinone (15.9 g), 4-vinylbenzyl glycidyl ether $(2.0 \mathrm{~g})$, tetraethyleneglycol mono-2-phenyl-2propenyl ether $(3.0 \mathrm{~g})$ and AIBN $(115.0 \mathrm{mg})$ were combined in chloroform $(12.0 \mathrm{~mL})$. The mixture was stirred for $24 \mathrm{~h}$ under reflux and then cooled to room temperature. The resulting polymer solution was slowly poured into methanol. The precipitated polymer was filtered, washed several times with methanol and then dried in vacuo for $24 \mathrm{~h}$ to afford the desired copolymer (2, $7.50 \mathrm{~g}, 91 \%$ yield). The molar ratio of the components was determined by ${ }^{1} \mathrm{H}$ NMR analysis (x:y:z = $63: 26: 11)$.

\subsubsection{Preparation of copolymer 3:}

Styrene (7.53 g, $72.3 \quad \mathrm{mmol}), \quad 2-[(2-$ phenylallyloxy)methyl]oxirane $\quad(1.72 \mathrm{~g}, \quad 9.04 \mathrm{mmol})$, tetraethyleneglycol mono-2-phenyl-2-propenyl ether (2.81 g, $9.04 \mathrm{mmol})$ and AIBN (105.9 mg) were combined in chloroform $(11.5 \mathrm{~mL})$. The mixture was stirred for $24 \mathrm{~h}$ under reflux and then cooled to room temperature. The resulting polymer solution was slowly poured into methanol. The precipitated polymer was filtered, washed several times with methanol and then dried for $24 \mathrm{~h}$ in vacuo to afford the desired copolymer (3, $7.35 \mathrm{~g}, 61 \%$ 
yield). The molar ratio of the components was determined by ${ }^{1} \mathrm{H}$ NMR analysis ( $\mathrm{x}: \mathrm{y}: \mathrm{z}=91: 5: 4)$.

\subsection{Preparation of polymer-incarcerated Au nanoclusters}

\subsubsection{Preparation of PI-Au 4a:}

Copolymer $3(198.5 \mathrm{mg})$ and $\mathrm{NaBH}_{4}(5.2 \mathrm{mg})$ were dissolved in THF $(2 \mathrm{~mL})$ at room temperature. To this solution was slowly added hydrogen tetrachloroaurate(III) tetrahydrate $(31.6 \mathrm{mg})$ with $2 \mathrm{~mL}$ of THF. The solution then turned purple. The mixture was stirred for $16 \mathrm{~h}$ at room temperature, and hexane $(30 \mathrm{~mL})$ was slowly added to the mixture at room temperature. Coaservates enveloped the metal dispersed in the medium. The catalyst capsules were washed with hexane several times and dried at room temperature. Next, the catalyst capsules were heated at 120 ${ }^{\circ} \mathrm{C}$ for $6 \mathrm{~h}$ without solvent to prepare purple polymer-incarcerated gold (PI-Au 4a, $189.8 \mathrm{mg}$, Au loading: $0.061 \mathrm{mmol} / \mathrm{g}$ ). PI-Au 4a was washed with THF and water. A $20-30 \mathrm{mg}$ sample of PI-Au 4a was heated in a mixture of sulfuric acid and nitric acid at 200 ${ }^{\circ} \mathrm{C}$ for $3 \mathrm{~h}$, the mixture was cooled to room temperature, and aqua regia was added. The amount of gold in the resulting solution was measured by ICP analysis to determine the Au loading.

\subsubsection{Preparation of PI-Au $4 \boldsymbol{b}$ :}

Copolymer $2(195.6 \mathrm{mg})$ and $\mathrm{NaBH}_{4}(8.6 \mathrm{mg})$ were dissolved in THF $(2 \mathrm{~mL})$ at room temperature. To this solution was slowly added hydrogen tetrachloroaurate $(\mathrm{III})$ tetrahydrate $(36.0 \mathrm{mg})$ with $2 \mathrm{~mL}$ of THF. The solution then turned purple. The mixture was stirred for $16 \mathrm{~h}$ at room temperature, and hexane $(30 \mathrm{~mL})$ was slowly added to the mixture at room temperature. Coaservates enveloped the metal dispersed in the medium. The catalyst capsules were washed with hexane several times and dried at room temperature. Next, the catalyst capsules were heated at 120 ${ }^{\circ} \mathrm{C}$ for $6 \mathrm{~h}$ without solvent to afford purple polymer-incarcerated gold (PI-Au 4b, $203.0 \mathrm{mg}$, Au loading: $0.217 \mathrm{mmol} / \mathrm{g}$ ). PI-Au $4 \mathbf{b}$ was washed with THF and water. A $20-30 \mathrm{mg}$ sample of PI-Au 4b was heated in a mixture of sulfuric acid and nitric acid at 200 ${ }^{\circ} \mathrm{C}$ for $3 \mathrm{~h}$, the mixture was cooled to room temperature, and aqua regia was added. The amount of gold in the resulting solution was measured by ICP analysis to determine the Au loading

\subsubsection{Preparation of PI-Au 4c:}

Copolymer $1(200.0 \mathrm{mg})$ and $\mathrm{NaBH}_{4}(4.5 \mathrm{mg})$ were dissolved in THF $(4 \mathrm{~mL})$ at room temperature. To this solution was slowly added chlorotriphenylphosphine gold (I) $(34.2 \mathrm{mg})$ with $2 \mathrm{~mL}$ of THF. The solution then turned purple. The mixture was stirred for $16 \mathrm{~h}$ at room temperature, and hexane $(30 \mathrm{~mL})$ was slowly added to the mixture at room temperature. Purple coaservates enveloped the metal dispersed in the medium. The catalyst capsules were then washed with hexane several times and dried at room temperature. Next, the catalyst capsules were heated at $150{ }^{\circ} \mathrm{C}$ for $5 \mathrm{~h}$ without solvent to prepare purple polymerincarcerated gold (PI-Au 4c, $222.3 \mathrm{mg}$, Au loading: 0.318 $\mathrm{mmol} / \mathrm{g}$ ). PI-Au 4c was washed with THF and water. A 20-30 mg sample of PI-Au 4c was heated in a mixture of sulfuric acid and nitric acid at $200{ }^{\circ} \mathrm{C}$ for $3 \mathrm{~h}$, the mixture was cooled to room temperature, and aqua regia was added. The amount of gold in the resulting solution was measured by ICP analysis to determine the Au loading.

\subsubsection{Preparation of $P I-A u$ 4f:}

Copolymer $1(200.0 \mathrm{mg})$ and $\mathrm{NaBH}_{4}(6.7 \mathrm{mg})$ were dissolved in THF $(4 \mathrm{~mL})$ at room temperature. To this solution was slowly added chlorotriphenylphosphine gold (I) $(31.1 \mathrm{mg})$ with $2 \mathrm{~mL}$ of THF. The solution then turned purple. The mixture was stirred for $16 \mathrm{~h}$ at room temperature, and hexane $(30 \mathrm{~mL})$ was slowly added to the mixture at room temperature. Purple coaservates enveloped the metal dispersed in the medium. The catalyst capsules were then washed with hexane several times and dried at room temperature. Next, the catalyst capsules were heated at $150{ }^{\circ} \mathrm{C}$ for $5 \mathrm{~h}$ without solvent to prepare purple polymerincarcerated gold (PI-Au 4f, $397.2 \mathrm{mg}$, Au loading: 0.079 $\mathrm{mmol} / \mathrm{g}$ ). PI-Au 4 f was washed with THF and water. A 20-30 mg sample of PI Au $\mathbf{4 b}$ was heated in a mixture of sulfuric acid and nitric acid at $200{ }^{\circ} \mathrm{C}$ for $3 \mathrm{~h}$, the mixture was cooled to room temperature, and aqua regia was added. The amount of gold in the resulting solution was measured by ICP analysis to determine the Au loading. Catalysts PI-Au 4d and $\mathbf{4 e}$ were also prepared by the same procedure; the only change made was to the amounts of chlorotriphenylphosphine gold (I) and $\mathrm{NaBH}_{4}$ used.

\subsubsection{Preparation of $P I-A u 4 g$ :}

Copolymer 1 (800.0 mg) and $\mathrm{NaBH}_{4}(12.3 \mathrm{mg})$ were dissolved in diglyme $(12 \mathrm{~mL})$ at room temperature. To this solution was slowly added chlorotriphenylphosphine gold (I) (31.3 mg) with $2 \mathrm{~mL}$ of diglyme. The solution then turned wine red. The mixture was stirred for $3 \mathrm{~h}$ at room temperature, and hexane $(30 \mathrm{~mL})$ was slowly added to the mixture at room temperature. Brown coaservates enveloped the metal dispersed in the medium. The catalyst capsules were then washed with hexane several times and dried at room temperature. Next, the catalyst capsules were heated at $150{ }^{\circ} \mathrm{C}$ for $5 \mathrm{~h}$ without solvent to give a wine red solid. The thus prepared solid was washed with dichloromethane and water, then crushed and dried to give a wine red powder. This powder was heated at $150{ }^{\circ} \mathrm{C}$ for $5 \mathrm{~h}$ without solvent to afford PI-Au 4g. A 20-30 mg sample of PI$\mathrm{Au} \mathbf{4 g}$ was heated in a mixture of sulfuric acid and nitric acid at $200{ }^{\circ} \mathrm{C}$ for $3 \mathrm{~h}$, the mixture was cooled to room temperature, and aqua regia was added. The amount of gold in the resulting solution was measured by ICP analysis to determine the Au loading $(0.080 \mathrm{mmol} / \mathrm{g})$.

\subsubsection{Preparation of $P I-A u$ 4h:}

Copolymer $1(800.0 \mathrm{mg})$ and $\mathrm{NaBH}_{4}(12.5 \mathrm{mg})$ were dissolved in diglyme $(14 \mathrm{~mL})$ at room temperature. To this solution was slowly added chlorotriphenylphosphine gold (I) $(29.1 \mathrm{mg}$ ) with $3 \mathrm{~mL}$ of THF. The solution then turned wine red. The mixture was stirred for $3 \mathrm{~h}$ at room temperature, and hexane $(30 \mathrm{~mL})$ was slowly added to the mixture at room temperature. Brown coaservates enveloped the metal dispersed in the medium. The catalyst capsules were then washed with diethyl ether several times and dried at room temperature. Next, the catalyst capsules were heated at $150{ }^{\circ} \mathrm{C}$ for $5 \mathrm{~h}$ without solvent to give a wine red solid. The solid thus prepared was washed with dichloromethane and water, then crushed and dried to afford a wine red powder. This powder was heated at $150{ }^{\circ} \mathrm{C}$ for $5 \mathrm{~h}$ without solvent to afford PI-Au 4h. A 20-30 mg sample of PI-Au $4 \mathbf{h}$ was heated in a mixture of sulfuric acid and nitric acid at $200{ }^{\circ} \mathrm{C}$ for $3 \mathrm{~h}$, the mixture was cooled to room temperature, and aqua regia was added. The amount of gold in the resulting solution was measured by ICP analysis to determine the Au loading (0.062 $\mathrm{mmol} / \mathrm{g})$.

\subsubsection{Preparation of PI-Au 4i:}

Copolymer $1(800.0 \mathrm{mg})$ and $\mathrm{NaBH}_{4}(12.0 \mathrm{mg})$ were dissolved in diglyme $(12 \mathrm{~mL})$ at room temperature. To this solution was slowly added chlorotriphenylphosphine gold (I) $(31.0 \mathrm{mg}$ ) with $2 \mathrm{~mL}$ of THF. The solution then turned wine red. The mixture was stirred for $3 \mathrm{~h}$ at room temperature, and diethyl ether $(30 \mathrm{~mL})$ was slowly added to the mixture at room temperature. Brown coaservates enveloped the metal dispersed in the medium. The catalyst capsules were then washed with diethyl ether several times and dried at room temperature. Next, the catalyst capsules were heated at $150{ }^{\circ} \mathrm{C}$ for $5 \mathrm{~h}$ without solvent to prepare a wine red solid. The solid thus prepared was 
washed with dichloromethane and water, then crushed and dried to give a wine red powder. This powder was heated at 150 ${ }^{\circ} \mathrm{C}$ for $5 \mathrm{~h}$ without solvent to afford PI-Au 4i. A $20-30 \mathrm{mg}$ sample of PI-Au $4 \mathbf{i}$ was heated in a mixture of sulfuric acid and nitric acid at $200{ }^{\circ} \mathrm{C}$ for $3 \mathrm{~h}$, the mixture was cooled to room temperature, and aqua regia was added. The amount of gold in the resulting solution was measured by ICP analysis to determine the Au loading $(0.073 \mathrm{mmol} / \mathrm{g})$.

\subsubsection{Preparation of $P I-A u \mathbf{4 j}$ :}

Copolymer $1(800.0 \mathrm{mg})$ and $\mathrm{NaBH}_{4}(12.0 \mathrm{mg})$ were dissolved in diglyme $(12 \mathrm{~mL})$ at room temperature. To this solution was slowly added chlorotriphenylphosphine gold (I) $(31.0 \mathrm{mg})$ with $2 \mathrm{~mL}$ of THF. The solution then turned wine red. The mixture was stirred for $3 \mathrm{~h}$ at room temperature, and diethyl ether $(30 \mathrm{~mL})$ was slowly added to the mixture at room temperature. Brown coaservates enveloped the metal dispersed in the medium. The catalyst capsules were then washed with diethyl ether and water several times, and dried at room temperature. Next, the catalyst capsules were heated at $150{ }^{\circ} \mathrm{C}$ for $5 \mathrm{~h}$ without solvent to prepare wine red solid. The solid thus prepared was washed with dichloromethane and water, then crushed and dried to afford a wine red powder. This powder was heated at $150{ }^{\circ} \mathrm{C}$ for $5 \mathrm{~h}$ without solvent to afford PI-Au 4j. A 20-30 mg sample of PI-Au $\mathbf{4 j}$ was heated in a mixture of sulfuric acid and nitric acid at $200{ }^{\circ} \mathrm{C}$ for $3 \mathrm{~h}$, the mixture was cooled to room temperature, and aqua regia was added. The amount of gold in the resulting solution was measured by ICP analysis to determine the Au loading $(0.071 \mathrm{mmol} / \mathrm{g})$.

\subsubsection{Crushing and $2^{\text {nd }}$ heating of PI-Au 4 i to PI- A и 4k-4p:}

PI-Au 4i was crushed using a pestle and a mortar. Crushed PI-Au was placed into a round-bottom flask and heated at $150{ }^{\circ} \mathrm{C}$ for $5 \mathrm{~h}$ without solvent to afford PI-Au 4l. The catalysts listed in Table 5 were prepared by the same procedure as for PI-Au $\mathbf{4 l}$.

\subsection{Oxidation reactions}

4.5.1. A typical procedure for homo-coupling of phenyl boronic acid catalyzed by PI-Au:

Phenyl boronic acid (60.6 mg, $0.5 \mathrm{mmol}), \mathrm{K}_{2} \mathrm{CO}_{3}(196.8 \mathrm{mg}$ ) and PI-Au 4 f $(0.079 \mathrm{mmol} / \mathrm{g}, 1 \mathrm{~mol} \%)$ were combined in water $(3.0 \mathrm{~mL})$ and DCM $(3 \mathrm{~mL})$. The mixture was stirred for $24 \mathrm{~h}$ under air at room temperature. The catalyst was collected by filtration and washed with EtOAc, then dried and reused. The aqueous layer was washed with EtOAc $(20 \mathrm{~mL})$. The yield was determined by GC analysis with reference to an internal standard (IS; anisole). After determining the yield, the solvents of both the aqueous and organic layers were removed in vacuo. Sulfuric acid and aqua regia were added to each residue. The volume of the residue was adjusted to $50 \mathrm{~mL}$, with water, to give a sample for ICP analysis, for the measurement of the leaching of gold.

4.5.2. A typical procedure for aerobic oxidation of alcohols catalyzed by PI-Au:

sec-Phenethyl alcohol $(63.1 \mathrm{mg}, 0.5 \mathrm{mmol}), \mathrm{K}_{2} \mathrm{CO}_{3}(206.8$ $\mathrm{mg})$ and PI-Au 4 f $(0.079 \mathrm{mmol} / \mathrm{g}, 3 \mathrm{~mol} \%)$ were combined in water $(3.0 \mathrm{~mL})$ and BTF $(3 \mathrm{~mL})$. After the mixture was stirred for $24 \mathrm{~h}$ under $\mathrm{O}_{2}$ at room temperature, the catalyst was collected by filtration and washed with EtOAc, then dried and reused. The aqueous layer was washed with EtOAc $(20 \mathrm{~mL})$. The yield was determined by GC analysis with reference to an IS (anisole). After determining the yield, the solvents of both aqueous and organic layers were removed in vacuo. Sulfuric acid and aqua regia were added to each residue. The volume of the residue was adjusted to $50 \mathrm{~mL}$, with water, to give a sample for ICP analysis, for the measurement of the leaching of gold.
4.5.3. Preparation of trimethyl(1-phenylprop-1enyloxy)silane: ${ }^{76}$

To diisopropylamine (5.6 g, $55 \mathrm{mmol})$ in THF $(100 \mathrm{~mL})$, $\mathrm{n}$ butyllithium (1.65 M hexane solution, $33 \mathrm{ml}, 55 \mathrm{mmol}$ ) was added at $0{ }^{\circ} \mathrm{C}$. After the mixture was cooled to $-78{ }^{\circ} \mathrm{C}$, propiophenone $(6.7 \mathrm{~g}, 50 \mathrm{mmol})$ in THF $(20 \mathrm{~mL})$ and trimethylsilyl chloride $(5.97 \mathrm{~g}, 55 \mathrm{mmol})$ were added dropwise, and the mixture was further stirred for $2 \mathrm{~h}$ at $0{ }^{\circ} \mathrm{C}$. Saturated aqueous ammonium chloride $(150 \mathrm{~mL})$ was added to quench the reaction, and the aqueous layer was extracted with hexane. The combined organic layers were dried over sodium sulfate, and the solvent was removed in vacuo. The residue was purified by flash column chromatography and by distillation to afford the silyl enol ether $(8.1 \mathrm{~g}, 80.4 \%)$. ${ }^{1} \mathrm{H}$ NMR $\left(\mathrm{CDCl}_{3}\right) \delta=0.00(\mathrm{~s}, 9 \mathrm{H})$, $1.60(\mathrm{~d}, 3 \mathrm{H}, J=6.9 \mathrm{~Hz}), 5.20$ (q, 1H, $J=7.0,13.7), 7.09$ (dd, $1 \mathrm{H}$, $J=6.3,13.8 \mathrm{~Hz}), 7.15(\mathrm{dd}, 2 \mathrm{H}, J=7.0 \mathrm{~Hz}), 7.32(\mathrm{~d}, 2 \mathrm{H}, J=7.4$ $\mathrm{Hz}) ;{ }^{13} \mathrm{C}$ NMR $\delta=0.5,11.7,125.1,127.2,128.5,133.0,149.8$.

4.5.4. A typical procedure for aerobic oxidation of silyl enol ether catalyzed by PI-Au 4I:

Trimethyl(1-phenylprop-1-enyloxy)silane $\quad(51.5 \mathrm{mg}, \quad 0.25$ mmol), PI-Au $4 \mathrm{l}(0.240 \mathrm{mmol} / \mathrm{g}, 1 \mathrm{~mol} \%)$, toluene $(1.0 \mathrm{~mL})$ and water $(1.0 \mathrm{~mL})$ were combined in a round-bottom flask. The mixture was stirred for $11 \mathrm{~h}$ under $\mathrm{O}_{2}$ at $80{ }^{\circ} \mathrm{C}$. After cooling to room temperature, the catalyst was collected by filtration and washed with ethyl acetate, using a Kiriyamarohto ${ }^{\circledR}$ funnel. The aqueous layer was extracted with ethyl acetate $(20 \sim 30 \mathrm{ml})$. The combined organic layers were dried over sodium sulfate. The yield was determined by GC analysis with reference to an internal standard (anisole).

4.5.5. Aerobic oxidation of 2-hydroxy-1phenylpropan-1-one catalyzed by PI-Au 4I:

2-Hydroxy-1-phenylpropan-1-one (5a) (37.5 mg, $0.25 \mathrm{mmol})$, PI-Au 41 ( $0.240 \mathrm{mmol} / \mathrm{g}, 1 \mathrm{~mol} \%)$, toluene $(1.0 \mathrm{~mL})$ and water $(1.0 \mathrm{~mL})$ were combined in a round-bottom flask. The mixture was stirred for $12 \mathrm{~h}$ under $\mathrm{O}_{2}$ at $80{ }^{\circ} \mathrm{C}$. The catalyst was collected by filtration and washed with ethyl acetate, using a Kiriyamarohto ${ }^{\circledR}$ funnel. The aqueous layer was extracted with ethyl acetate $(20 \sim 30 \mathrm{ml})$. The combined organic layers were dried over sodium sulfate. The yield was determined by GC analysis with reference to an internal standard (anisole).

4.5.6. Aerobic oxidation of 1-phenylpropane-1,2dione catalyzed by $\mathrm{PI}-\mathrm{Au} \mathbf{4 l}$ :

1-Phenylpropane-1,2-dione (5b) $(37.0 \mathrm{mg}, 0.25 \mathrm{mmol}), \mathrm{PI}-\mathrm{Au}$ $4 \mathrm{l}(0.240 \mathrm{mmol} / \mathrm{g}, 1 \mathrm{~mol} \%)$, toluene $(1.0 \mathrm{~mL})$ and water $(1.0 \mathrm{~mL})$ were combined in a round-bottom flask. After the mixture was stirred for $18 \mathrm{~h}$ under $\mathrm{O}_{2}$ at $80{ }^{\circ} \mathrm{C}$, the catalyst was collected by filtration and washed with ethyl acetate, using a Kiriyamarohto ${ }^{\circledR}$ funnel. The aqueous layer was extracted with ethyl acetate $(20 \sim 30 \mathrm{ml})$. The combined organic layers were dried over sodium sulfate. The yield was determined by GC analysis with reference to an internal standard (anisole).

\subsubsection{Aerobic oxidation of propiophenone catalyzed by $P I-A u$ 4I:}

Propiophenone (5c) (33.5 mg, $0.25 \mathrm{mmol})$, PI-Au $4 \mathbf{l}(0.240$ $\mathrm{mmol} / \mathrm{g}, 1 \mathrm{~mol} \%)$, toluene $(1.0 \mathrm{~mL})$ and water $(1.0 \mathrm{~mL})$ were combined in a round-bottom flask. The mixture was stirred for $18 \mathrm{~h}$ under $\mathrm{O}_{2}$ at $80{ }^{\circ} \mathrm{C}$. The catalyst was collected by filtration and washed with ethyl acetate, using a Kiriyamarohto ${ }^{\circledR}$ funnel. The aqueous layer was extracted with ethyl acetate $(20 \sim 30 \mathrm{ml})$. The combined organic layers were dried over sodium sulfate. The yield was determined by GC analysis with reference to an internal standard (anisole). 
4.5.8. Aerobic oxidation of 1-phenyl-2(trimethylsilyloxy)propan-1-one catalyzed by PI-Au 4l:

1-Phenyl-2-(trimethylsilyloxy)propan-1-one (5f) $(55.5 \mathrm{mg}$, $0.25 \mathrm{mmol}), \mathrm{PI}-\mathrm{Au} 4 \mathrm{l}(0.240 \mathrm{mmol} / \mathrm{g}, 1 \mathrm{~mol} \%)$, toluene $(1.0 \mathrm{~mL})$ and water $(1.0 \mathrm{~mL})$ were combined in a round-bottom flask. The mixture was stirred for $15 \mathrm{~h}$ under $\mathrm{O}_{2}$ at $80{ }^{\circ} \mathrm{C}$. The catalyst was collected by filtration and washed with ethyl acetate, using a Kiriyamarohto ${ }^{\circledR}$ funnel. The aqueous layer was extracted with ethyl acetate $(20 \sim 30 \mathrm{ml})$. The combined organic layers were dried over sodium sulfate. The yield was determined by GC analysis with reference to an internal standard (anisole).

\section{Acknowledgements}

This work was partially supported by a Grant-in-Aid for Scientific Research from JSPS, MEXT (Japan), JST, NEDO, METI and The University of Tokyo. T. Y. thanks JSPS for the Research Fellowship for Young Scientists. We thank Mr. Noriaki Kuramitsu (The University of Tokyo) for STEM and EDS analyses.

\section{References}

1. Haruta, M.; Kobayashi, T.; Sano, H.; Yamada, N. Chem. Lett. 1987, 2, 405-408.

2. Haruta, M.; Yamada, N.; Kobayashi, T.; Iijima, S. J. Catal. 1989, 115, 301-309.

3. Arcadi, A. Chem. Rev. 2008, 108, 3266-3325.

4. Corma, A.; García, H. Chem. Soc. Rev. 2008, 37, 2096-2126.

5. Della Pina, C.; Falletta, E.; Prati, L.; Rossi, M. Chem. Soc. Rev. 2008, 37, 2077-2095.

6. Li, Z. G.; Brouwer, C.; He, C. Chem. Rev. 2008, 108, 3239-3265.

7. Corma, A.; Leyva-Pérez, A.; Sabater, M. J. Chem. Rev. 2011, 111, 1657-1712.

8. Ishida, T.; Haruta, M. Angew. Chem., Int. Ed. 2007, 46, 7154-7156.

9. Tsukuda, T.; Tsunoyama, H.; Sakurai, H. Chem. Asian J. 2011, 6, 736-748.

10. Dimitratos, N.; Lopez-Sanchez, J. A.; Hutchings, G. J. Chem. Sci. 2012, 3, 20-44.

11. Aschwanden, L.; Mallat, T.; Maciejewski, M.; Krumeich, F.; Baiker, A. ChemCatChem 2010, 2, 666-673.

12. So, M.-H.; Liu, Y.; Ho, C.-M.; Che, C.-M. Chem. Asian J. 2009, 4, 1551-1561.

13. Grirrane, A.; Corma, A.; Garcia, H. J. Catal. 2009, 264, 138-144.

14. Zhu, B.; Angelici, R. J. Chem. Commun. 2007, 2157-2159.

15. Carrettin, S.; Guzman, J.; Corma, A. Angew. Chem., Int. Ed. 2005, 44, 2242-2245.

16. Chaicharoenwimolkul, L.; Munmai, A.; Chairam, S.; Tewasekson, U.; Sapudom, S.; Lakliang, Y.; Somsook, E. Tetrahedron Lett. 2008, 49, 7299-7302.

17. Tsunoyama, H.; Sakurai, H.; Ichikuni, N.; Negishi, Y.; Tsukuda, T. Langmuir 2004, 20, 11293-11296.

18. Willis, N. G.; Guzman, J. Appl. Catal. A: General 2008, 339, 6875.

19. Gao, L.; Nishikata, T.; Kojima, K.; Chikama, K.; Nagashima, H. Chem. Asian J. 2013, 8, 3152-3163.

20. Akiyama, R.; Kobayashi, S. Chem. Rev. 2009, 109, 594-642.

21. Kobayashi, S.; Miyamura, H. Chem. Rec. 2010, 10, 271-290.

22. Kobayashi, S.; Miyamura, H. Aldrichimica Acta 2013, 46, 3-19.

23. Kobayashi, S.; Nagayama, S. J. Am. Chem. Soc. 1998, 120, $2985-$ 2986.

24. Akiyama, R.; Kobayashi, S. J. Am. Chem. Soc. 2003, 125, 3412 3413.

25. Yuan, H.; Yoo, W.-J.; Miyamura, H.; Kobayashi, S. Adv. Synth. Catal. 2012, 354, 2899-2904.

26. Yuan, H.; Yoo, W.-J.; Miyamura, H.; Kobayashi, S. J. Am. Chem. Soc. 2012, 134, 13970-13973.

27. Yoo, W.-J.; Yuan, H.; Miyamura, H.; Kobayashi, S. Can. J. Chem. 2012, 90, 306-313

28. Yoo, W.-J.; Yuan, H.; Miyamura, H.; Kobayashi, S. Adv. Synth. Catal. 2011, 353, 3085-3089.

29. Miyamura, H.; Maehata, K.; Kobayashi, S. Chem. Commun. 2010, $46,8052-8054$.
30. Miyamura, H.; Shiramizu, M.; Matsubara, R.; Kobayashi, S Angew. Chem., Int. Ed. 2008, 47, 8093-8095.

31. Nishio, R.; Sugiura, M.; Kobayashi, S. Org. Biomol. Chem. 2006 , 4, 992-995.

32. Okamoto, K.; Akiyama, R.; Yoshida, H.; Yoshida, T.; Kobayashi, S. J. Am. Chem. Soc. 2005, 127, 2125-2135.

33. Soulé, J.-F.; Miyamura, H.; Kobayashi, S. J. Am. Chem. Soc. 2013, 135, 10602-10605.

34. Yasukawa, T.; Miyamura, H.; Kobayashi, S. J. Am. Chem. Soc. 2012, 134, 16963-16966.

35. Conte, M.; Miyamura, H.; Kobayashi, S.; Chechik, V. J. Am. Chem. Soc. 2009, 131, 7189-7196.

36. Conte, M.; Miyamura, H.; Kobayashi, S.; Chechik, V. Chem. Commun. 2010, 46, 145-147.

37. Lucchesi, C.; Inasaki, T.; Miyamura, H.; Matsubara, R.; Kobayashi, S. Adv. Synth. Catal. 2008, 350, 1996-2000.

38. Miyamura, H.; Kobayashi, S. Chem. Lett. 2012, 41, 976-978.

39. Miyamura, H.; Matsubara, R.; Miyazaki, Y.; Kobayashi, S. Angew. Chem., Int. Ed. 2007, 46, 4151-4154.

40. Miyamura, H.; Morita, M.; Inasaki, T.; Kobayashi, S. Bull. Chem. Soc. Jpn. 2011, 84, 588-599.

41. Miyamura, H.; Shiramizu, M.; Matsubara, R.; Kobayashi, S. Chem. Lett. 2008, 37, 360-361.

42. Miyamura, H.; Yasukawa, T.; Kobayashi, S. Green Chem. 2010, 12, 776-778.

43. Soulé, J.-F.; Miyamura, H.; Kobayashi, S. J. Am. Chem. Soc. 2011, 133, 18550-18553.

44. Soulé, J.-F.; Miyamura, H.; Kobayashi, S. Asian J. Org. Chem. 2012, 1, 319-321.

45. Soulé, J.-F.; Miyamura, H.; Kobayashi, S. Chem. Asian J. 2013, 8, 2614-2626.

46. Wang, N.; Matsumoto, T.; Ueno, M.; Miyamura, H.; Kobayashi, S. Angew. Chem., Int. Ed. 2009, 48, 4744-4746.

47. Yasukawa, T.; Miyamura, H.; Kobayashi, S. Chem. Asian J. 2011, 6, 621-627.

48. Kaizuka, K.; Lee, K.-Y.; Miyamura, H.; Kobayashi, S. J. Flow Chem. 2012, 2, 1-4.

49. Kaizuka, K.; Miyamura, H.; Kobayashi, S. J. Am. Chem. Soc. 2010, 132, 15096-15098.

50. Miyamura, H.; Matsubara, R.; Kobayashi, S. Chem. Commun. 2008, 2031-2033.

51. Soulé, J.-F.; Miyamura, H.; Kobayashi, S. Chem. Commun. 2013, 49, 355-357.

52. Yoo, W.-J.; Miyamura, H.; Kobayashi, S. J. Am. Chem. Soc. 2011, 133, 3095-3103.

53. Miyamura, H.; Choo, G. C. Y.; Yasukawa, T.; Yoo, W.-J.; Kobayashi, S. Chem. Commun. 2013, 49, 9917-9919.

54. Miyamura, H.; Kobayashi, S. Acc. Chem. Res. 2014, 47, 1054.

55. Nakazawa, M.; Somorjai, G. A. Appl. Surf. Sci. 1993, 68, 517-537.

56. Kumar, A.; Mandal, S.; Mathew, S. P.; Selvakannan, P. R.; Mandale, A. B.; Chaudhari, R. V.; Sastry, M. Langmuir 2002, 18, 6478-6483.

57. Ramanath, G.; D'Arcy-Gall, J.; Maddanimath, T.; Ellis, A. V.; Ganesan, P. G.; Goswami, R.; Kumar, A.; Vijayamohanan, K. Langmuir 2004, 20, 5583-5587.

58. Maddanimath, T.; Kumar, A.; D'Arcy-Gall, J.; Ganesan, P. G.; Vijayamohanan, K.; Ramanath, G. Chem. Commun. 2005, 14351437.

59. Kobayashi, J.; Mori, Y.; Okamoto, K.; Akiyama, R.; Ueno, M.; Kitamori, T.; Kobayashi, S. Science 2004, 304, 1305-1308.

60. Kobayashi, S.; Miyamura, H.; Akiyama, R.; Ishida, T. J. Am. Chem. Soc. 2005, 127, 9251-9254.

61. Tsunoyama, H.; Sakurai, H.; Negishi, Y.; Tsukuda, T. J. Am. Chem. Soc. 2005, 127, 9374-9375.

62. Clark, R. D.; Heathcock, C. H. Tetrahedron Lett. 1974, 15, 2027 2030.

63. Rubottom, G. M.; Vazquez, M. A.; Pelegrina, D. R. Tetrahedron Lett. 1974, 15, 4319-4322.

64. Hassner, A.; Reuss, R. H.; Pinnick, H. W. J. Org. Chem. 1975, 40, 3427-3429.

65. Rubottom, G. M.; Gruber, J. M. J. Org. Chem. 1978, 43, 15991602 .

66. Rubottom, G. M.; Gruber, J. M.; Mong, G. M. J. Org. Chem. 1976, 41, 1673-1674.

67. McCormick, J. P.; Tomasik, W.; Johnson, M. W. Tetrahedron Lett. 1981, 22, 607-610.

68. Moriarty, R. M.; Prakash, O.; Duncan, M. P. Synthesis 1985, 1985, 943-944.

69. Davis, F. A.; Sheppard, A. C. J. Org. Chem. 1987, 52, 954-955 
70. Zhu, Y.; Yong, T.; Hongwu, Y.; Yian, S. Tetrahedron Lett. 1998, 39, 7819-7822.

71. Li, H.-J.; Zhao, J.-L.; Chen, Y.-J.; Liu, L.; Wang, D.; Li, C.-J. Green Chem. 2005, 7, 61-63.

72. Rubottom, G. M.; Lopez Nieves, M. I. Tetrahedron Lett. 1972, 13, 2423-2425.

73. Brook, A. G.; Macrae, D. M. J. Organomet. Chem. 1974, 77, C19C21.

74. Brown, H. C.; Mead, E. J.; Subba Rao, B. C. J. Am. Chem. Soc. 1955, 77, 6209-6213.

75. Akiyama, R.; Sagae, T.; Sugiura, M.; Kobayashi, S. J. Organomet. Chem. 2004, 689, 3806-3809.

76. Ishikawa, S.; Hamada, T.; Manabe, K.; Kobayashi, S. J. Am. Chem. Soc. 2004, 126, 12236-12237. 
Graphical Abstract

To create your abstract, type over the instructions in the template box below.

Fonts or abstract dimensions should not be changed or altered.

Preparation of polymer incarcerated gold nanocluster $\quad$ Leave this area blank for abstract info. catalysts (PI-Au) and their application to aerobic oxidation reactions of byronic acids, alcohols, and sibyl enol aethers

Hiroyuki Miyamura, Tomohiro Yasukawa, Shū Kobayashi*

Department of Chemistry, School of Science, The University of Tokyo, Kongo, Bunkyo-ku, Tokyo, 113-0033 (Japan)

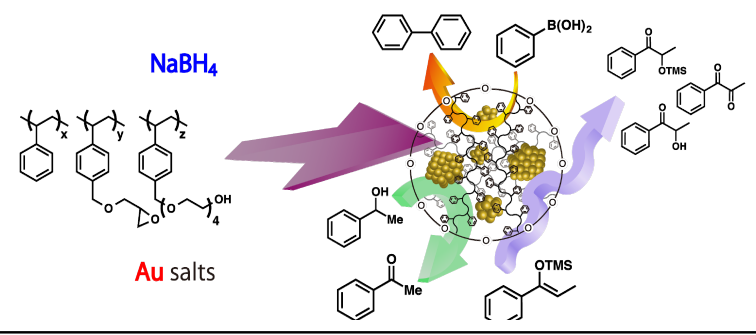

